Article

\title{
Weinreb Amidation as the Cornerstone of an Improved Synthetic Route to A-Ring-Modified Derivatives of Luotonin A
}

\section{Norbert Haider * and Simon Nuß}

Department of Drug and Natural Product Synthesis, Faculty of Life Sciences, University of Vienna, Althanstraße 14, A-1090 Vienna, Austria

* Author to whom correspondence should be addressed; E-Mail: norbert.haider@univie.ac.at; Tel.: +43-1-4277-55624; Fax: +43-1-4277-9556.

Received: 21 August 2012; in revised form: 14 September 2012 / Accepted: 18 September 2012 / Published: 25 September 2012

\begin{abstract}
Weinreb amidation of ethyl 4-oxo-3,4-dihydroquinazoline-2-carboxylate with aromatic amines provides a significantly improved route to anilide-type key intermediates for the synthesis of the anticancer alkaloid, luotonin A, and new A-ring-modified derivatives thereof. This method has advantages concerning overall yield, brevity, and versatility with regard to the aromatic amine component, even if the latter has less favourable nucleophilicity, solubility and/or stability properties. This is demonstrated by the concise synthesis of a small library of luotonin A analogues, including a novel thiophene isostere of the alkaloid.
\end{abstract}

Keywords: Weinreb amidation; luotonin A; [4+2] cycloaddition; thiophene

\section{Introduction}

Since the isolation of the alkaloid luotonin A (Figure 1) from the plant Peganum nigellastrum Bunge (Zygophyllaceae) in 1997 [1] and the discovery of its cytotoxic activity, which is based on stabilisation of the DNA-topoisomerase-I complex and is thus similar to that of the closely related natural product, camptothecin (CPT; Figure 1), there have been various reports describing the total synthesis and biological evaluation of luotonin $\mathrm{A}$ and compounds derived thereof (for reviews on luotonin A and related natural products, see refs. [2-5]). These synthetic approaches include the assembly of a pyrroloquinoline fragment (rings ABC) with an anthranilic acid synthon [6] as well as free-radical cyclisation reactions [7,8] or Pd-catalysed CC coupling reactions [9] as the key step, the 
latter usually with final formation of ring $\mathrm{C}$ (for a comprehensive overview of all the synthetic strategies employed so far, cf. ref. [5]).

Figure 1. Structures of luotonin A (with IUPAC-conforming numbering) and camptothecin.

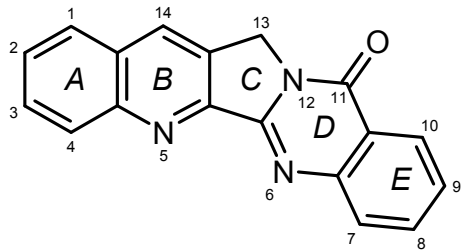

Luotonin A

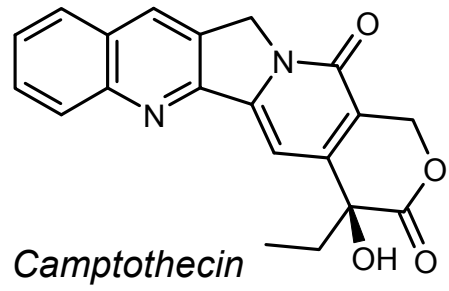

As it has become quite evident that modification of ring $\mathrm{A}$ is highly interesting with respect to achieving enhanced cytotoxicity [5], synthetic approaches which utilise easily accessible and highly variable A-ring building blocks are of particular value. In this context, three different methods employing aniline or substituted anilines as such synthons have been developed. In Batey's approach [10], the key step is an intramolecular aza-Diels-Alder reaction of an imine-containing azadiene with a propargyl dienophile, mediated by dysprosium triflate (an application of the Povarov reaction). Closely related is a one-pot reaction recently published by $\mathrm{Chu}$ [11] which gives luotonin A or some derivatives thereof, albeit in modest yields, from isatoic anhydride, propargylamine, glyoxal and anilines in the presence of ytterbium triflate. In our hands, the cycloaddition approach reported by Yao [12] (Scheme 1) gave the highest overall yields and it worked most reliably in the final cycloaddition key step.

Scheme 1. Yao's total synthesis of luotonin A [12].
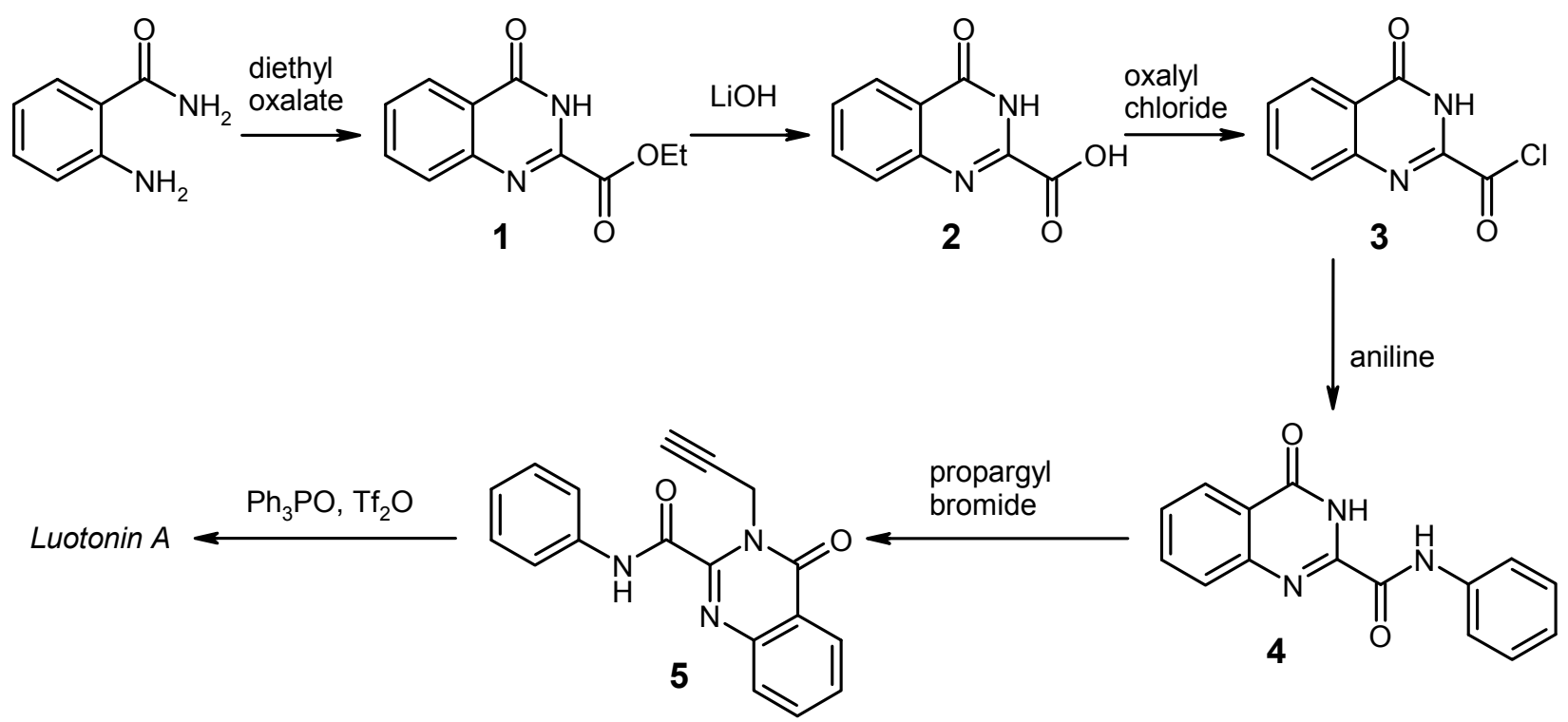

This route is based on the generation of the requisite azadiene from an anilide structure $\mathbf{5}$ by treatment with Hendrickson's reagent [bis(triphenyl)oxodiphosphonium trifluoromethanesulfonate, prepared in situ from triphenylphosphine oxide and trifluoromethanesulfonic anhydride]. In Yao's protocol [12], the intermediate anilide 4 is prepared by saponification of ethyl 4-oxo-3,4-dihydroquinazoline-2-carboxylate (1) [13-15] with lithium hydroxide in aqueous tetrahydrofuran, followed by 
treatment of the carboxylic acid $\mathbf{2}$ with oxalyl chloride and subsequent reaction of the acid chloride $\mathbf{3}$ thus obtained with aniline/sodium bicarbonate in dichloromethane.

\section{Results and Discussion}

When we sought to employ this protocol for the preparation of a small library of new luotonin A derivatives bearing various substituents at ring $\mathrm{A}$, we soon found out that the sequence of ester hydrolysis/acid chloride formation/aminolysis constitutes a serious bottleneck for two reasons: (a) the free carboxylic acid $\mathbf{2}$ is almost insoluble in most solvents, but it is highly sensitive towards decarboxylation, and special care has to be taken during the preparation and work-up of this intermediate; (b) the reaction of the very sparingly soluble acid chloride $\mathbf{3}$ with aromatic amines can also be problematic, especially if they have less favourable properties than aniline in terms of nucleophilicity, solubility, and/or stability. In order to overcome these limitations, we have now developed a highly efficient alternative route for the preparation of these key intermediates which enabled us to synthesize a series of A-ring modified luotonin A derivatives, including a novel thiophene analogue of the lead compound.

In a first attempt to circumvent the solubility problems mentioned above, we reversed the order of the two steps, $\mathrm{N}$-alkylation (with propargyl bromide) and ester hydrolysis (Scheme 2). However, this approach met with failure: hydrolysis of the $N$-propargyl ester 6 with lithium hydroxide in aqueous tetrahydrofuran at room temperature or below always resulted in immediate decarboxylation of the initially formed carboxylic acid upon neutralisation ( $\mathrm{pH} 7$ ), leading to the 2-unsubstituted quinazolinone 7, which is known from literature [13-15].

Scheme 2. Hydrolysis of the ester $\mathbf{6}$, followed by spontaneous decarboxylation.

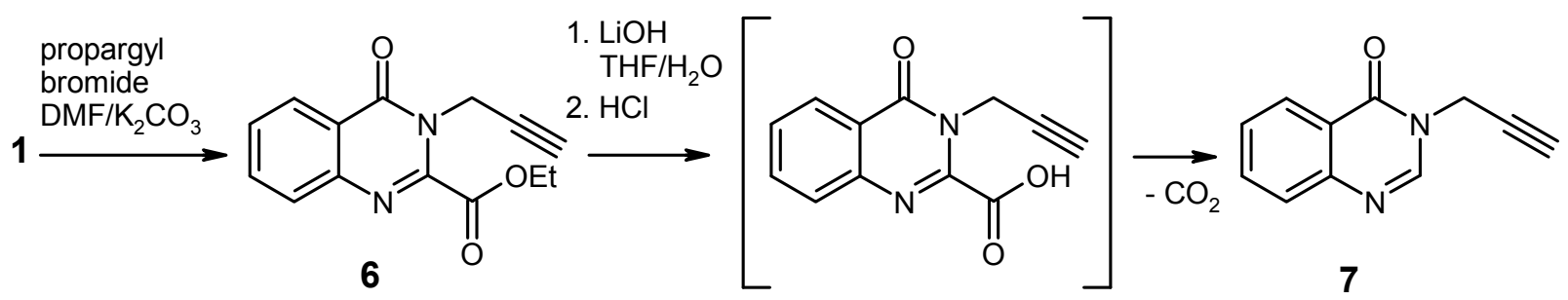

Consequently, we envisaged direct transformation of the ester function into the corresponding anilide as a general and versatile solution of this problem. Weinreb's method [16,17] for amide synthesis from esters and (aliphatic or aromatic) amines by activation of the amine component with trimethylaluminium appeared to be an attractive option. Indeed, when the $N$-propargyl ester 6 was reacted with $\mathrm{AlMe}_{3}$-activated aniline in 1,2-dichloroethane solution (this solvent had been reported to be superior [18]), slow formation of the anilide was detected by TLC. However, the reaction could not be brought to completion even after prolonged refluxing and by using a larger excess of reagent. We assume steric hindrance of the ester group by the adjacent propargyl moiety to be responsible for this insufficient reactivity. Therefore, the $N-3$ unsubstituted ester 1 was chosen as a more promising substrate for Weinreb amidation. It turned out that this approach indeed gives excellent results: typically, $\mathbf{1}$ is completely consumed within 1-2 hours of refluxing, and the corresponding anilides $\mathbf{4}$ are 
obtained in $>90 \%$ yield (Scheme 3). This applies even to sparingly soluble and/or electron-poor anilines like 4-nitroaniline or 4-aminobenzonitrile. After quenching of the amidation reactions with aqueous acid, the products $\mathbf{4}$ are typically isolated simply by filtration.

For the subsequent N-alkylation step with propargyl bromide, we again had to modify Yao's protocol [12] in order to circumvent solubility problems with some of the substituted anilides 4 . Instead of the liquid/liquid two-phase method (toluene/water, tetrabutylammonium bromide as phasetransfer catalyst), we used dimethyl formamide/potassium carbonate as a reaction medium, which reliably gave the products (5) in yields between 54\% and 86\% (Scheme 3).

Scheme 3. Two-step synthesis of the key intermediates 5 from the ester $\mathbf{1}$.

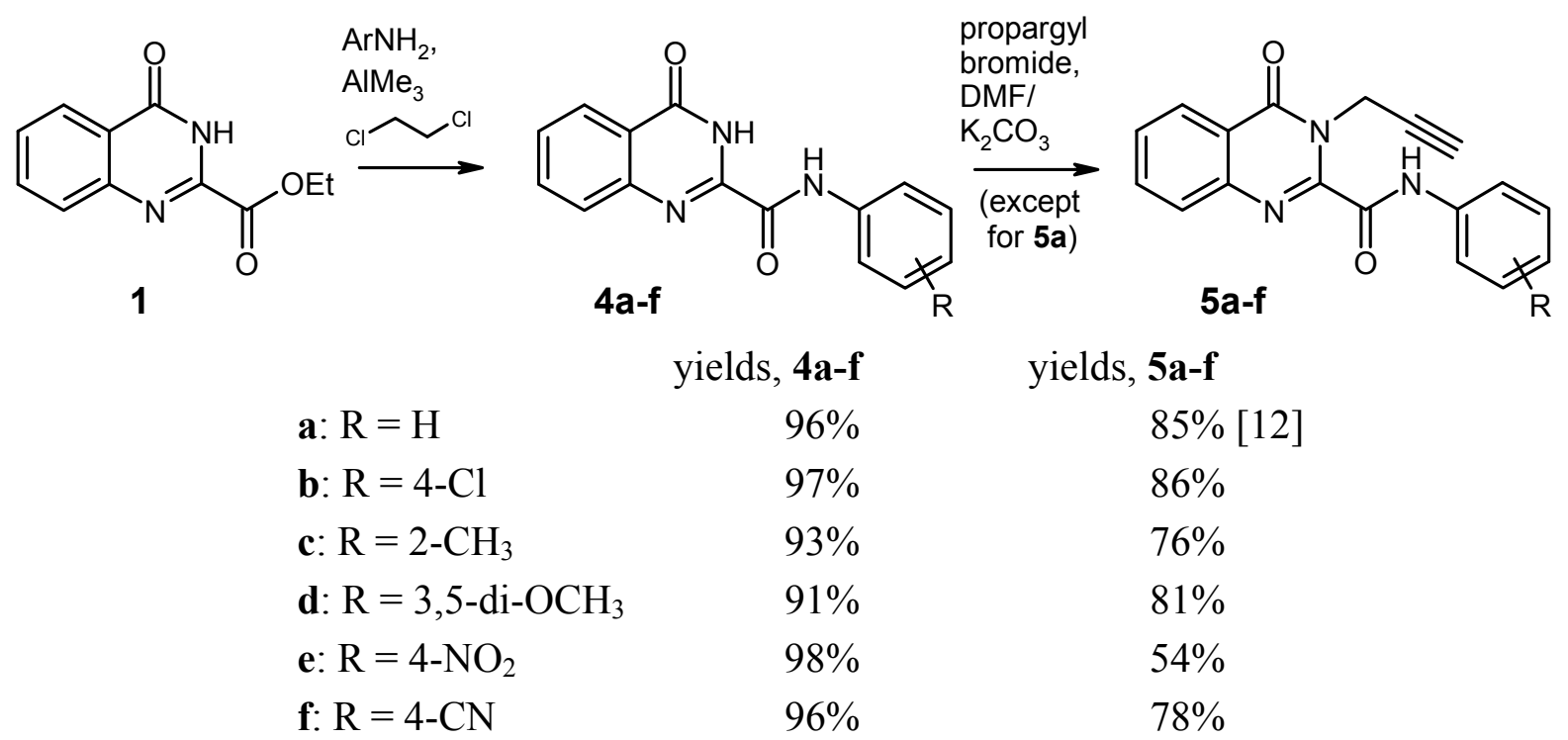

With this optimised pathway to the 3-substituted quinazolinone-2-carboxylic acid anilides $\mathbf{5}$ now available, we prepared several of these cycloaddition educts and subjected them to the cycloaddition conditions [12] (triphenylphosphine oxide, triflic anhydride, dry dichloromethane as solvent; see Scheme 4). In most cases, the intramolecular aza-Diels-Alder reaction takes place very smoothly at room temperature within one hour. Thus, the known compounds luotonin A (8a) [1], 2-chloroluotonin A (8b) [19], and 4-methylluotonin A (8c) [11] as well as the new analogue 1,3-dimethoxyluotonin A (8d) were prepared in high yields (82-99\%). When the aniline unit bears a strongly electronwithdrawing and solubility-decreasing group, as it is the case with the 4-nitroanilide 5e and the 4-cyanoanilide $\mathbf{5 f}$, the cycloaddition proceeds somewhat less efficiently, affording the hitherto unknown 3-nitroluotonin A (8e) and 3-cyanoluotonin A (8f) in 69\% and 54\% yield, respectively, along with some unreacted educt [20].

In order to further explore the scope and limitations of this concise route to luotonin A derivatives, we briefly investigated its suitability for generating heterocyclic A-ring analogues, using 4-aminopyridine and 2-aminothiophene as building blocks. While the former is commercially available and undergoes Weinreb amidation with 1 very smoothly to afford the $N$-(4-pyridyl)amide 9 (Scheme 5), the latter amine is rather unstable and rapidly decomposes after isolation as the free base. We used a modification of Binder's method [21] for the preparation of 2-aminothiophene by deprotection of $\mathrm{N}$-BOC-2-aminothiophene, employing a mixture of dichloromethane and trifluoroacetic acid at $0{ }^{\circ} \mathrm{C}$. 
Instead of attempting to isolate the free amine, we simply washed the organic solution with aqueous sodium carbonate and subsequently performed a solvent exchange from dichloromethane to 1,2-dichloroethane, keeping the temperature below $20{ }^{\circ} \mathrm{C}$ all the time. After drying, this solution of 2-aminothiophene is well-suited for use in the Weinreb amidation, thus affording the $N$-(2-thienyl)amide 11 in 95\% yield (Scheme 5).

Scheme 4. Synthesis of luotonin A derivatives by intramolecular cycloaddition of compounds $\mathbf{5}$.

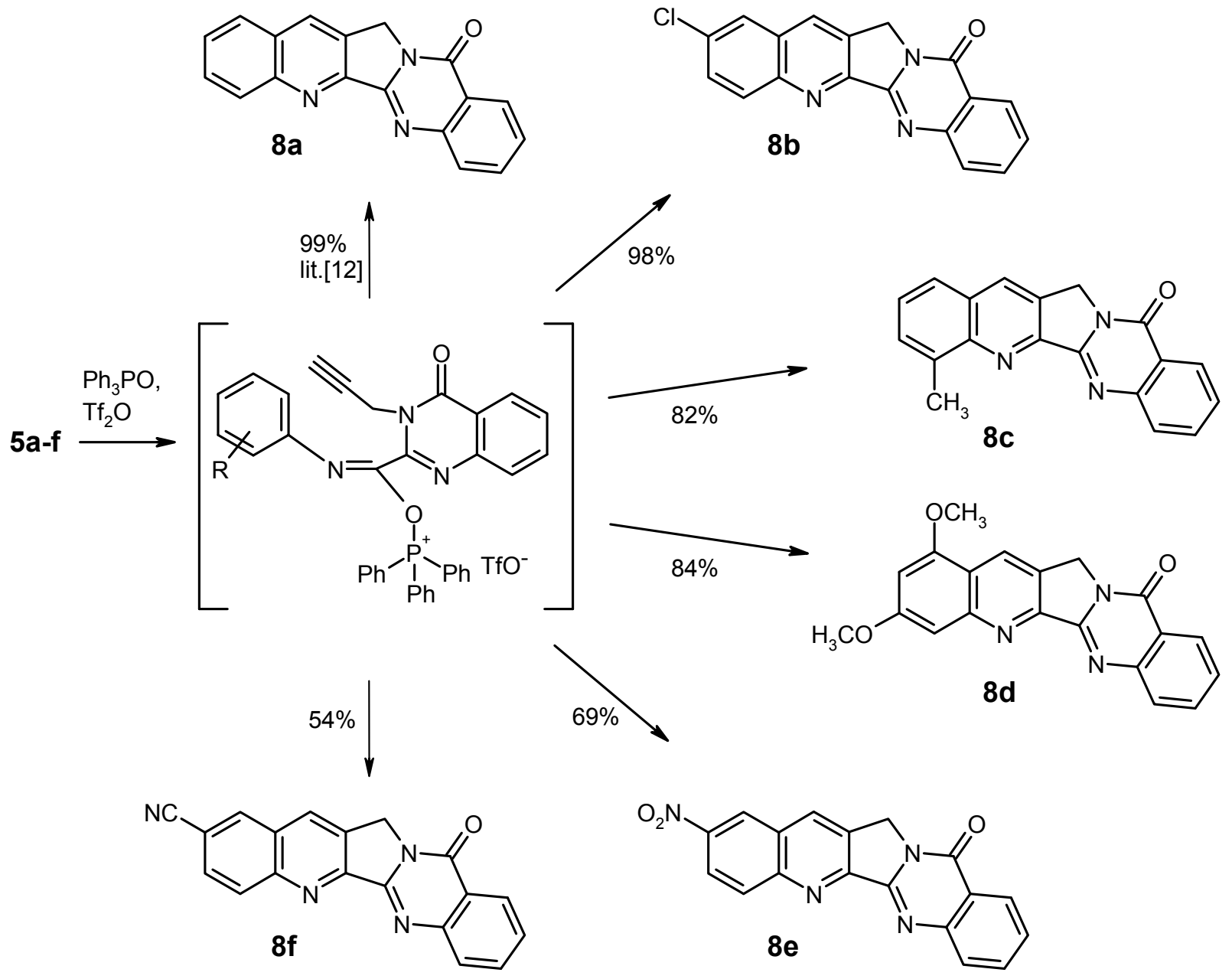

Both of the $N$-(hetaryl)amides $\mathbf{9 , 1 1}$ were selectively alkylated at the quinazolinone nitrogen with propargyl bromide in analogy to the preparation of compounds 5. However, attempted intramolecular cycloaddition by treatment with Hendrickson's reagent showed that the pyridine derivative $\mathbf{1 0}$ does not react under these conditions: only unchanged starting material and triphenylphosphine oxide were recovered (a tiny TLC spot with an intense blue fluorescence indicated that traces of the 2-azaluotonin A might have been formed, though). On the other hand, we succeeded in the transformation of the thiophene intermediate $\mathbf{1 2}$ into the desired pentacyclic compound $\mathbf{1 3}$ in reasonable yield (55\%), the latter product representing a novel thiophene isoster of luotonin A [22].

Preliminary in-vitro screening (using the Resazurin assay [23]) for antiproliferative activity towards six different human tumor cell lines showed that $\mathbf{1 3}$ is practically inactive, whereas $\mathbf{8 d}$ exhibits a slightly better activity profile than that of the lead compound, luotonin A [24]. More detailed biological investigations are intended. 
Scheme 5. Preparation and (attempted) cyclisation of heterocyclic analogues.

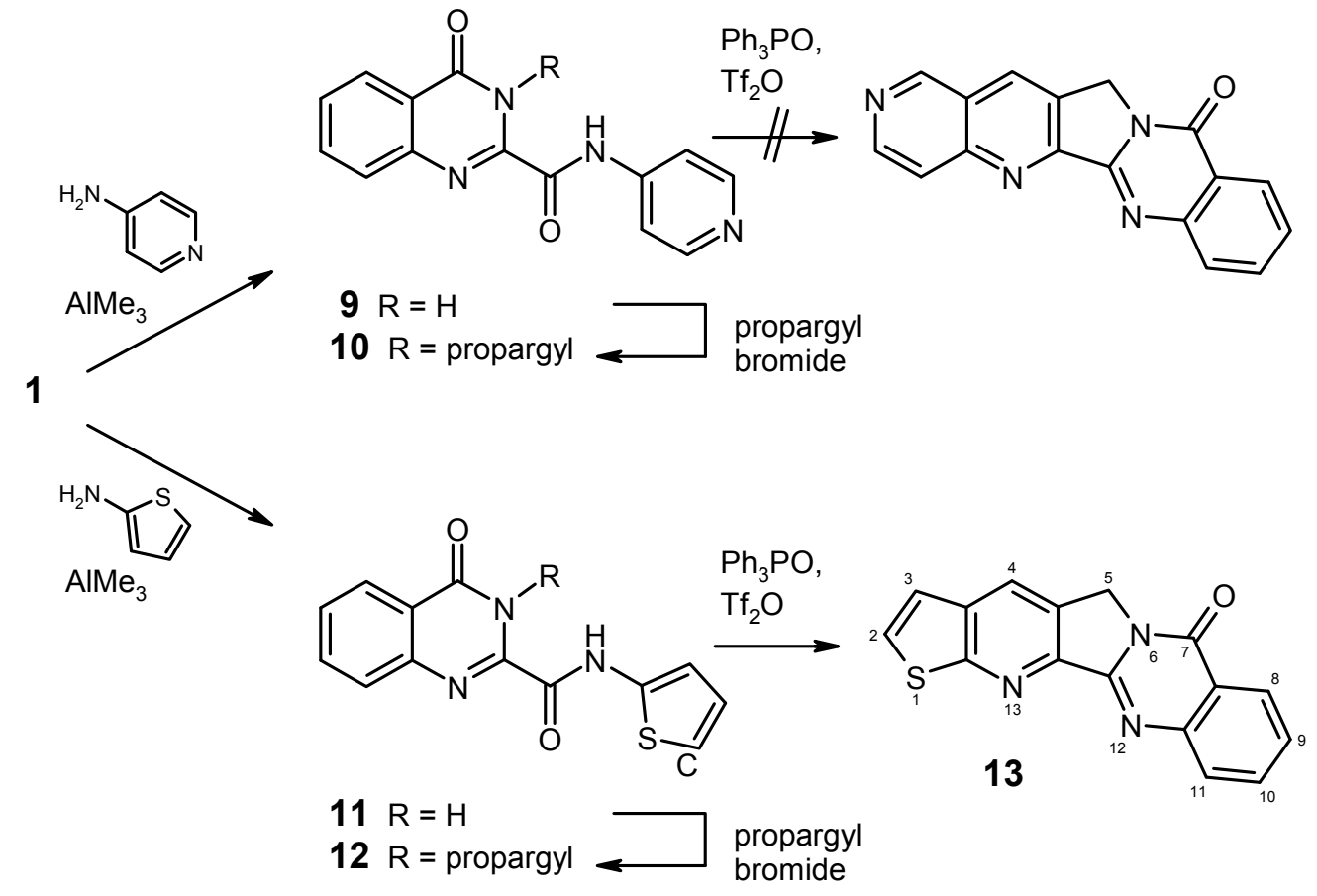

\section{Experimental}

\section{General}

Melting points (uncorrected) were determined on a Kofler hot-stage microscope (Reichert). ${ }^{1} \mathrm{H}-\mathrm{NMR}$ and ${ }^{13} \mathrm{C}-\mathrm{NMR}$ spectra were recorded on a Varian UnityPlus 300 spectrometer at $300 \mathrm{MHz}$ and $75 \mathrm{MHz}$, respectively. IR spectra were taken on a Perkin-Elmer 1605 FT-IR instrument. Mass spectra were obtained on a Shimadzu QP5050A DI 50 instrument, high-resolution mass spectra were recorded on a Finnigan MAT 8230 spectrometer at the Institute of Organic Chemistry, University of Vienna. Column chromatography was carried out on Merck Kieselgel 60, 0.063-0.200 mm, thin layer chromatography was done on Merck aluminium sheets pre-coated with Kieselgel $60 \quad F_{254}$. Microanalyses were performed at the Microanalytical Laboratory, Faculty of Chemistry, University of Vienna. Compounds 5a and $\mathbf{8 a}$ were prepared according to lit.[12].

Ethyl 4-oxo-3-(prop-2-yn-1-yl)-3,4-dihydroquinazoline-2-carboxylate (6). To a solution of ethyl 4-oxo3,4-dihydroquinazoline-2-carboxylate [13-15] (1, $1.004 \mathrm{~g}, 4.6 \mathrm{mmol})$ in dimethylformamide $(20 \mathrm{~mL})$ was added $\mathrm{K}_{2} \mathrm{CO}_{3}(759 \mathrm{mg}, 5.5 \mathrm{mmol})$ and propargyl bromide $(818 \mathrm{mg}$ of an $80 \%$ solution in toluene, $5.5 \mathrm{mmol}$ ), and the mixture was stirred at room temperature for $4 \mathrm{~h}$. It was then poured into ice-water $(50 \mathrm{~mL})$ and extracted with ethyl acetate $(3 \times 50 \mathrm{~mL})$. The combined extracts were washed with brine, dried over $\mathrm{Na}_{2} \mathrm{SO}_{4}$ and evaporated under reduced pressure to afford an oily residue. Trituration with cold ethanol gave the product $(1.110 \mathrm{~g}, 94 \%)$ as colourless crystals, mp 93-94 ${ }^{\circ} \mathrm{C}(\mathrm{EtOH})$. MS (EI, $\left.70 \mathrm{eV}\right)$ m/z: $256\left(\mathrm{M}^{+}, 88 \%\right), 227$ (100), 184 (74), 183 (44), 155 (75), 130 (46), 129 (69), 102 (41); ${ }^{1} \mathrm{H}-\mathrm{NMR}$ $\left(\mathrm{CDCl}_{3}\right) \delta: 8.34(\mathrm{~d}, J=7.9 \mathrm{~Hz}, 1 \mathrm{H}, 5-\mathrm{H}), 7.86-7.76(\mathrm{~m}, 2 \mathrm{H}, 7-\mathrm{H}, 8-\mathrm{H}), 7.63-7.54(\mathrm{~m}, 1 \mathrm{H}, 6-\mathrm{H}), 5.17(\mathrm{~d}$, $\left.J=2.4 \mathrm{~Hz}, 2 \mathrm{H}, \mathrm{NCH}_{2}\right), 4.56\left(\mathrm{q}, J=7.2 \mathrm{~Hz}, 2 \mathrm{H}, \mathrm{OC}_{2} \mathrm{CH}_{3}\right), 2.32(\mathrm{t}, J=2.4 \mathrm{~Hz}, 1 \mathrm{H}, \mathrm{C} \equiv \mathrm{CH}), 1.49$ (t, $\left.J=7.2 \mathrm{~Hz}, 3 \mathrm{H}, \mathrm{OCH}_{2} \underline{\mathrm{CH}}_{3}\right) ;{ }^{13} \mathrm{C}-\mathrm{NMR}\left(\mathrm{CDCl}_{3}\right) \delta: 161.3,160.5,146.1,145.6,135.0,128.9,128.5$, 
127.4, 121.9, 73.3, 63.7, 33.3, 14.1. Anal. Calcd. for $\mathrm{C}_{14} \mathrm{H}_{12} \mathrm{~N}_{2} \mathrm{O}_{3}$ : C, 65.62; $\mathrm{H}, 4.72 ; \mathrm{N}, 10.93$. Found: C, $65.63 ; \mathrm{H}, 4.74 ; \mathrm{N}, 10.82$.

Hydrolysis/Decarboxylation of the Ester 6. To an ice-cooled solution of the ester 6 (512 mg, $2 \mathrm{mmol})$ in THF $(10 \mathrm{~mL})$ was added water $(3 \mathrm{~mL})$ and $\mathrm{LiOH}$ monohydrate $(126 \mathrm{mg}, 3 \mathrm{mmol})$ and the mixture was stirred at $0{ }^{\circ} \mathrm{C}$ for $10 \mathrm{~min}$. The solution was concentrated under reduced pressure to approx. $3 \mathrm{~mL}$ and it was then diluted with ice-cold water $(7 \mathrm{~mL})$, neutralised with $1 \mathrm{~N} \mathrm{HCl}$, and extracted with ethyl acetate $(3 \times 20 \mathrm{~mL})$. The combined extracts were washed with brine, dried over $\mathrm{Na}_{2} \mathrm{SO}_{4}$ and evaporated under reduced pressure to give 3-(prop-2-yn-1-yl)quinazolin-4(3H)-one [13] (7, $287 \mathrm{mg}$, 93\%) as an oily residue which slowly solidified; recrystallisation from methanol afforded colourless crystals of mp $115-116{ }^{\circ} \mathrm{C}$ (lit. [13] mp $116-118{ }^{\circ} \mathrm{C}$, lit. [14] mp $\left.115-116{ }^{\circ} \mathrm{C}\right) .{ }^{1} \mathrm{H}-\mathrm{NMR}\left(\mathrm{CDCl}_{3}\right) \delta$ : 8.35-8.26 (m, 2H, 2-H, 5-H), 7.82-7.69 (m, 2H, 7-H, 8-H), 7.51 (dd, $J=6.5 \mathrm{~Hz}, 1.9 \mathrm{~Hz}, 1 \mathrm{H}, 6-\mathrm{H})$, $4.81\left(\mathrm{~d}, J=2.5 \mathrm{~Hz}, \mathrm{CH}_{2}\right), 2.49(\mathrm{t}, J=2.5 \mathrm{~Hz}, 1 \mathrm{H}, \mathrm{C} \equiv \mathrm{CH})$.

General Procedure for the Synthesis of the Anilides 4 by Weinreb Amidation. To a solution of the corresponding aniline $(8 \mathrm{mmol})$ in dry 1,2-dichloroethane $(20 \mathrm{~mL})$ under argon was added dropwise a $2 \mathrm{M}$ solution of $\mathrm{AlMe}_{3}(4.0 \mathrm{~mL}, 8 \mathrm{mmol})$ in heptane. The mixture was stirred for $30 \mathrm{~min}$ at room temperature, then the ester $1(1.091 \mathrm{~g}, 5 \mathrm{mmol})$ was added in one portion, and the mixture was refluxed for $2 \mathrm{~h}$. After cooling to $0{ }^{\circ} \mathrm{C}$, it was then quenched by slow addition of $2 \mathrm{~N} \mathrm{HCl}(20 \mathrm{~mL})$, followed by water $(80 \mathrm{~mL})$. The resulting liquid/liquid/solid system was filtered and the filter cake was washed with $70 \% \mathrm{EtOH}$ and dried. An additional amount of product was obtained by exhaustive extraction of the filtrate with $\mathrm{CH}_{2} \mathrm{Cl}_{2}$, washing of the extract with water, drying over $\mathrm{Na}_{2} \mathrm{SO}_{4}$ and evaporation. The combined portions of crude product were recrystallised from an appropriate solvent (see below).

4-Oxo-N-phenyl-3,4-dihydroquinazoline-2-carboxamide [12,25] (4a). Yield: $1.240 \mathrm{~g}$ (93\%), colourless crystals, mp 247-248 ${ }^{\circ} \mathrm{C}(\mathrm{EtOH})$ (lit. [25] mp $\left.178{ }^{\circ} \mathrm{C}\right)$. MS (EI, $\left.70 \mathrm{eV}\right) \mathrm{m} / \mathrm{z}: 265\left(\mathrm{M}^{+}, 47 \%\right), 223$ (11), 146 (100), 119 (67), 118 (15), 91 (15), 90 (20), 77 (8), 65 (12); ${ }^{1} \mathrm{H}-\mathrm{NMR}$ (DMSO-d $)$ ): 12.50 (br s, $1 \mathrm{H}, 3-\mathrm{H}), 10.76$ (s, 1H, amide-H), 8.20 (dd, $J=7.7 \mathrm{~Hz}, 1.1 \mathrm{~Hz}, 1 \mathrm{H}, 5-\mathrm{H}), 7.94-7.85$ (m, 4H, 7-H, 8-H, phenyl 2'-H, 6'-H), 7.65-7.61 (m, 1H, 6-H, shows NOE on irradiation at $8.20 \mathrm{ppm}), 7.39(\mathrm{t}, J=7.8 \mathrm{~Hz}$, $2 \mathrm{H}$, phenyl $\left.3^{\prime}-\mathrm{H}, 5^{\prime}-\mathrm{H}\right), 7.19-7.14\left(\mathrm{~m}, 1 \mathrm{H}\right.$, phenyl $\left.4^{\prime}-\mathrm{H}\right) ;{ }^{13} \mathrm{C}-\mathrm{NMR}$ (DMSO-d $) \delta: 161.1,158.1,146.8$, $146.1,137.7,134.8,128.8,128.2,127.7,126.2,124.6,122.7,120.6$.

N-(4-Chlorophenyl)-4-oxo-3,4-dihydroquinazoline-2-carboxamide (4b). Yield: 1.450 g (97\%), colourless crystals, mp 294-295 ${ }^{\circ} \mathrm{C}\left(\mathrm{DMF} \mathrm{CHCl}_{3}\right)$. IR (KBr): 3322, 3232, 3136, 3116, 1714, 1706, 1696, 1684, 1590, 1540, 1492, 1402, 1312, 840, 816, 768, $496 \mathrm{~cm}^{-1}$; MS (EI, $\left.70 \mathrm{eV}\right) \mathrm{m} / \mathrm{z}: 301\left(\mathrm{M}^{+}\right.$, 13\%), 300 (7), $299\left(\mathrm{M}^{+}, 38\right), 146$ (48), 119 (100), 91 (11), 90 (21), 63 (10); ${ }^{1} \mathrm{H}-\mathrm{NMR}$ (DMSO- $\left.d_{6}\right) \delta$ : 12.52 (s, 1H, 3-H), 10.93 (s, 1H, amide-H), 8.19 (d, $J=7.2 \mathrm{~Hz}, 1 \mathrm{H}, 5-\mathrm{H}), 7.94-7.87$ (m, 4H, 7-H, 8-H, phenyl 2'-H, 6'-H, shows NOE on irradiation at $10.93 \mathrm{ppm}), 7.66-7.61 \mathrm{~m}, 1 \mathrm{H}, 6-\mathrm{H}$, shows NOE on irradiation at $8.19 \mathrm{ppm}$ ), 7.48-7.43 (AA' part of an $\mathrm{AA}^{\prime} \mathrm{BB}^{\prime}$ system, $2 \mathrm{H}$, phenyl $\left.3^{\prime}-\mathrm{H}, 5^{\prime}-\mathrm{H}\right)$; ${ }^{13} \mathrm{C}-\mathrm{NMR}$ $\left(\mathrm{DMSO}_{-} d_{6}\right) \delta$ : 161.1, 158.2, 146.7, 146.0, 136.6, 134.7, 128.6, 128.3, 128.2, 127.6, 126.2, 122.7, 122.2. HRMS (EI, $70 \mathrm{eV}) \mathrm{m} / z$ calcd. for $\mathrm{C}_{15} \mathrm{H}_{11} \mathrm{ClN}_{3} \mathrm{O}_{2}\left([\mathrm{M}+\mathrm{H}]^{+}\right)$: 300.0540 . Found: 300.0550 . 
N-(2-Methylphenyl)-4-oxo-3,4-dihydroquinazoline-2-carboxamide (4c). Yield: 1.298 g (93\%), colourless crystals, mp $215-21{ }^{\circ} \mathrm{C}\left(\mathrm{DMF} / \mathrm{CHCl}_{3}\right)$. IR (KBr): 3350, 3132, 3062, 1678, 1604, 1590, 1542, 1444, 1334, 896, 772, $668 \mathrm{~cm}^{-1}$; MS (EI, $\left.70 \mathrm{eV}\right) \mathrm{m} / z$ : 279 (M+1, 35\%), 251 (44), 146 (44), 120 (28), 119 (100), 118 (22), 91 (20), 90 (27); ${ }^{1} \mathrm{H}-\mathrm{NMR}$ (DMSO- $d_{6}$ ) $\delta: 12.51$ (s, 1H, 3-H), 10.36 (s, 1H, amide-H), 8.19 (dd, $J=8.1 \mathrm{~Hz}, 1.2 \mathrm{~Hz}, 1 \mathrm{H}, 5-\mathrm{H}), 7.94-7.83$ (m, 2H, 7-H, 8-H), 7.86-7.60 (m, 2H, 6-H, phenyl $6^{\prime}-\mathrm{H}$, shows NOE on irradiation at $10.36 \mathrm{ppm}$ or at $\left.8.19 \mathrm{ppm}\right), 7.31-7.25\left(\mathrm{~m}, 1 \mathrm{H}\right.$, phenyl $\left.3^{\prime}-\mathrm{H}\right)$, 7.25-7.14 (m, 2H, phenyl 4'-H, 5'-H), 2.31 (s, 3H, $\left.\mathrm{CH}_{3}\right) ;{ }^{13} \mathrm{C}-\mathrm{NMR}$ (DMSO- $d_{6}$ ) $\delta: 161.2,157.8,146.6$, 146.0, 135.1, 134.7, 131.5, 130.4, 128.1, 127.6, 126.2, 126.1, 125.9, 124.1, 122.6, 17.5. HRMS (EI, $70 \mathrm{eV}$ ) $m / z$ calcd. for $\mathrm{C}_{16} \mathrm{H}_{14} \mathrm{~N}_{3} \mathrm{O}_{2}\left([\mathrm{M}+\mathrm{H}]^{+}\right): 280.1086$. Found: 280.1089 .

N-(3,5-Dimethoxyphenyl)-4-oxo-3,4-dihydroquinazoline-2-carboxamide (4d). Yield: $1.480 \mathrm{~g}$ (91\%), colourless crystals, mp $228-229^{\circ} \mathrm{C}\left(\mathrm{CHCl}_{3}\right)$. IR (KBr): 3334, 3130, 3076, 3002, 2938, 1672, 1600, 1548, 1466, 1444, 1416, 1334, 1200, 1152, 1064, 1056, 892, 812, 776, 680, $566 \mathrm{~cm}^{-1}$; MS (EI, $\left.70 \mathrm{eV}\right)$ m/z: 326 (14\%), $325\left(\mathrm{M}^{+}, 100\right), 310$ (16), 294 (43), 283 (12), 179 (17), 146 (36), 119 (71), 90 (22); ${ }^{1} \mathrm{H}-\mathrm{NMR}\left(\mathrm{DMSO}-d_{6}\right) \delta$ : 12.49 (s, 1H, 3-H), 10.67 (s, 1H, amide-H), 8.19 (d, J = 9.6 Hz, 1H, 5-H), 7.94-7.87 (m, 2H, 7-H, 8-H), 7.66-7.60 (m, 1H, 6-H), 7.19 (d, J=2.1 Hz, 2H, phenyl 2'-H, 6'-H, shows NOE on irradiation at $10.67 \mathrm{ppm}), 6.32\left(\mathrm{t}, J=2.1 \mathrm{~Hz}, 1 \mathrm{H}\right.$, phenyl 4'-H) $3.75\left(\mathrm{~s}, 6 \mathrm{H}, \mathrm{OCH}_{3}\right)$; ${ }^{13} \mathrm{C}-\mathrm{NMR}\left(\mathrm{DMSO}-d_{6}\right) \delta: 161.1,160.4,158.0,146.6,145.9,139.2,134.7,128.2,127.6,126.2,122.6$, 98.7, 96.6, 55.2. HRMS (EI, $70 \mathrm{eV}) \mathrm{m} / z$ calcd. for $\mathrm{C}_{17} \mathrm{H}_{16} \mathrm{~N}_{3} \mathrm{O}_{4}\left([\mathrm{M}+\mathrm{H}]^{+}\right): 326.1141$. Found: 326.1145.

$\mathrm{N}$-(4-Nitrophenyl)-4-oxo-3,4-dihydroquinazoline-2-carboxamide (4e). Yield: $1.521 \mathrm{~g}$ (98\%), colourless crystals, $\mathrm{mp}>330{ }^{\circ} \mathrm{C}$ (DMF). IR (KBr): 3292, 3254, 3116, 1718, 1698, 1606, 1554, 1514, 1484, 1450 , 1412, 1336, 1308, 1232, 1184, 1146, 1108, 994, 898, 858, 770, 750, 718, 686, 664, 594, 546, 526, $490 \mathrm{~cm}^{-1}$; MS (EI, $\left.70 \mathrm{eV}\right) \mathrm{m} / z: 310\left(\mathrm{M}^{+}, 57 \%\right), 146$ (100), 145 (15), 119 (100), 118 (19), 91 (16), 90 (28), 57 (15); ${ }^{1} \mathrm{H}-\mathrm{NMR}$ (DMSO- $d_{6}$ ) $\delta: 12.63$ (s, 1H, 3-H), 11.33 (s, 1H, amide-H), 8.32-8.28 (BB' part of an AA'BB' system, 2H, phenyl 3'-H, 5'-H), 8.23-8.16 (m, 3H, 5-H, phenyl 2'-H, 6'-H, shows NOE on irradiation at $11.33 \mathrm{ppm}), 7.97-7.88(\mathrm{~m}, 2 \mathrm{H}, 7-\mathrm{H}, 8-\mathrm{H}), 7.69-7.63(\mathrm{~m}, 1 \mathrm{H}, 6-\mathrm{H}) ;{ }^{13} \mathrm{C}-\mathrm{NMR}$ (DMSO- $\left.d_{6}\right)$ $\delta: 160.9,158.8,146.7,145.5,143.8,143.2,134.8,128.5,127.9,126.2,124.7,122.9$, 120.5. HRMS (EI, $70 \mathrm{eV}) \mathrm{m} / z$ calcd. for $\mathrm{C}_{15} \mathrm{H}_{10} \mathrm{~N}_{4} \mathrm{O}_{4}\left(\mathrm{M}^{+}\right): 310.0702$. Found: 310.0710 .

N-(4-Cyanophenyl)-4-oxo-3,4-dihydroquinazoline-2-carboxamide (4f). Yield: 1.392 g (96\%), colourless crystals, mp 322-324 ${ }^{\circ} \mathrm{C}$ (DMF). IR (KBr): 3304, 3256, 2224, 1720, 1688, 1604, 1590, 1536, 1484 , 1466, 1446, 1412, 1320, 1232, 1176, 1142, 1120, 896, 840, 770, 710, 684, 600, 550, 506, $460 \mathrm{~cm}^{-1}$; MS (EI, $70 \mathrm{eV}$ ) m/z: 290 (M+, 42\%), 146 (69), 119 (100), 118 (25), 91 (25), 90 (63), 64 (21), 63 (21); ${ }^{1} \mathrm{H}-\mathrm{NMR}\left(\mathrm{DMSO}-d_{6}\right) \delta: 12.61(\mathrm{~s}, 1 \mathrm{H}, 3-\mathrm{H}), 11.18(\mathrm{~s}, 1 \mathrm{H}$, amide-H), 8.19 (dd, $J=7.5 \mathrm{~Hz}, 0.8 \mathrm{~Hz}, 1 \mathrm{H}$, 5-H), 8.11-8.08 (BB' part of an AA'BB' system, 2H, phenyl 3'-H, 5'-H), 7.92-7.84 (m, 4H, 7-H, 8-H, phenyl $\left.2^{\prime}-\mathrm{H}, 66^{\prime}-\mathrm{H}\right), 7.67-7.61$ (m, 1H, 6-H); ${ }^{13} \mathrm{C}-\mathrm{NMR}$ (DMSO- $d_{6}$ ) $\delta: 161.2,158.8,146.6,145.7$, 141.9, 134.7, 133.1, 128.3, 127.7, 126.2, 122.8, 120.7, 118.8, 106.4. HRMS (EI, $70 \mathrm{eV}) \mathrm{m} / \mathrm{z}$ calcd. for $\mathrm{C}_{16} \mathrm{H}_{10} \mathrm{~N}_{4} \mathrm{O}_{2}\left(\mathrm{M}^{+}\right): 290.0804$. Found: 290.0812.

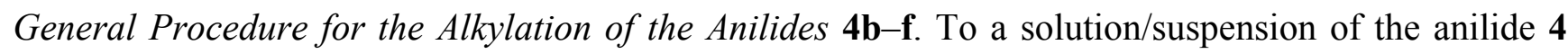
( $3 \mathrm{mmol}$ ) in DMF $\left(20 \mathrm{~mL}\right.$ ) was added $\mathrm{K}_{2} \mathrm{CO}_{3}(455 \mathrm{mg}, 3.3 \mathrm{mmol})$ and propargyl bromide (490 $\mathrm{mg}$ of an $80 \%$ solution in toluene, $3.3 \mathrm{mmol}$ ), and the mixture was stirred at room temperature for $24 \mathrm{~h}$ 
(in the case of $\mathbf{4 e}$ and $\mathbf{4 f}$, the reaction time was $48 \mathrm{~h}$ and the reagents were added in two equal portions of $1.65 \mathrm{mmol}$, one at the beginning and another one after $24 \mathrm{~h}$ ). The mixture was poured into water $(200 \mathrm{~mL})$ and it was exhaustively extracted with $\mathrm{CH}_{2} \mathrm{Cl}_{2}$. The combined extracts were washed with water and brine, dried over $\mathrm{Na}_{2} \mathrm{SO}_{4}$, and evaporated. The residue was triturated with a little $\mathrm{CHCl}_{3}$ and recrystallised from an appropriate solvent (see below).

$\mathrm{N}$-(4-Chlorophenyl)-4-oxo-3-(prop-2-yn-1-yl)-3,4-dihydroquinazoline-2-carboxamide (5b). Yield: $870 \mathrm{mg}$ (86\%), colourless crystals, mp 186-189 ${ }^{\circ} \mathrm{C}\left(\mathrm{CHCl}_{3}\right)$. IR (KBr): 3300, 3264, 3190, 3124, 3070, 3004, 2970, 1686, 1656, 1602, 1586, 1568, 1542, 1490, 1474, 1466, 1422, 1388, 1336, 1312, 1240, 1166, 1092, 1010, 946, 902, 828, 790, 768, 698, 650, 562, 516, $498 \mathrm{~cm}^{-1}$; MS (EI, $\left.70 \mathrm{eV}\right) \mathrm{m} / \mathrm{z}: 338\left([\mathrm{M}-1]^{+}\right.$, 38\%), $336\left([\mathrm{M}-1]^{+}, 100\right), 308$ (51), 302 (77), 155 (42), 129 (48), 119 (57), 90 (44); ${ }^{1} \mathrm{H}-\mathrm{NMR}\left(\mathrm{CDCl}_{3}\right)$ $\delta$ : $9.73(\mathrm{~s}, 1 \mathrm{H}$, amide-H), 8.35 (d, $J=8.1 \mathrm{~Hz}, 1 \mathrm{H}, 5-\mathrm{H}), 7.87-7.81(\mathrm{~m}, 1 \mathrm{H}, 7-\mathrm{H}), 7.79-7.76(\mathrm{~m}, 1 \mathrm{H}$, 8-H), 7.74-7.67 (BB' part of an $\mathrm{AA}^{\prime} \mathrm{BB}^{\prime}$ system, 2H, phenyl 2'-H, 6'-H, shows NOE on irradiation at $9.73 \mathrm{ppm}), 7.65-7.58(\mathrm{~m}, 1 \mathrm{H}, 6-\mathrm{H}$, shows NOE on irradiation at $8.73 \mathrm{ppm}), 7.41-7.35$ ( $\mathrm{AA}^{\prime}$ part of an AA'BB' system, 2H, phenyl 3'-H, 5'-H), $5.58\left(\mathrm{~d}, J=2.4 \mathrm{~Hz}, 2 \mathrm{H}, \mathrm{CH}_{2}\right), 2.28(\mathrm{t}, J=2.4 \mathrm{~Hz}, 1 \mathrm{H}, \mathrm{C} \equiv \mathrm{CH})$; ${ }^{13} \mathrm{C}-\mathrm{NMR}\left(\mathrm{CDCl}_{3}\right) \delta: 161.1,158.1,145.0,144.8,135.4,135.0,130.4,129.2,129.1,127.7,127.5$, 121.7, 121.3, 78.8, 72.0, 33.6. HRMS (EI, $70 \mathrm{eV}$ ) $\mathrm{m} / z$ calcd. for $\mathrm{C}_{18} \mathrm{H}_{11} \mathrm{ClN}_{3} \mathrm{O}_{2}\left([\mathrm{M}-\mathrm{H}]^{+}\right)$: 338.0696 . Found: 338.0703.

N-(2-Methylphenyl)-4-oxo-3-(prop-2-yn-1-yl)-3,4-dihydroquinazoline-2-carboxamide (5c). Yield: $724 \mathrm{mg}$ (76\%), colourless crystals, mp 208-210 ${ }^{\circ} \mathrm{C}\left(\mathrm{CHCl}_{3}\right)$. IR (KBr): 3230, 3058, 2922, 1680, 1660, 1600, 1544, 1476, 1458, 1424, 1386, 1326, 1310, 1240, 1172, 1046, 1026, 976, 948, 914, 858, 810, 772, 744, 692, 622, 592, 546, $502 \mathrm{~cm}^{-1}$; MS (EI, $\left.70 \mathrm{eV}\right) \mathrm{m} / \mathrm{z}: 317\left(\mathrm{M}^{+}, 19 \%\right), 316$ (36), 303 (21), 302 (100), 289 (24), 288 (45), 144 (28), 129 (30), 119 (37); ${ }^{1} \mathrm{H}-\mathrm{NMR}\left(\mathrm{CDCl}_{3}\right)$ 8: 9.69 (s, 1H, amide-H, shows NOE on irradiation at $2.44 \mathrm{ppm}), 8.37(\mathrm{~d}, J=7.5 \mathrm{~Hz}, 1 \mathrm{H}, 5-\mathrm{H}$, shows NOE on irradiation at 7.64-7.59 ppm), $8.09\left(\mathrm{~d}, J=8.1 \mathrm{~Hz}, 1 \mathrm{H}\right.$, phenyl $6^{\prime}-\mathrm{H}$, shows NOE on irradiation at $\left.9.69 \mathrm{ppm}\right), 7.87-7.82(\mathrm{~m}, 1 \mathrm{H}, 7-\mathrm{H}$, shows NOE on irradiation at 7.64-7.59 ppm), $7.77(\mathrm{~d}, J=7.5 \mathrm{~Hz}, 1 \mathrm{H}, 8-\mathrm{H}), 7.64-7.59$ (m, 1H, 6-H, shows NOE on irradiation at $8.37 \mathrm{ppm}), 7.32-7.26(\mathrm{~m}, 2 \mathrm{H}$, phenyl 5'-H, 3'-H, shows NOE on irradiation at $2.44 \mathrm{ppm}$, on irradiation at $8.09 \mathrm{ppm}$, or on irradiation at 7.18-7.13 ppm), 7.18-7.13 (m, $1 \mathrm{H}$, phenyl $\left.4^{\prime}-\mathrm{H}\right), 5.62\left(\mathrm{~d}, J=2.4 \mathrm{~Hz}, 2 \mathrm{H}, \mathrm{CH}_{2}\right), 2.44\left(\mathrm{~s}, 3 \mathrm{H}, \mathrm{CH}_{3}\right.$, shows NOE on irradiation at 9.69 ppm), 2.28 $(\mathrm{t}, J=2.4 \mathrm{~Hz}, 1 \mathrm{H}, \mathrm{C} \equiv \mathrm{CH}) ;{ }^{13} \mathrm{C}-\mathrm{NMR}\left(\mathrm{CDCl}_{3}\right) \delta: 161.2,158.3,145.5,144.9,134.9,134.8,130.6$, 129.0, 128.9, 127.8, 127.5, 126.9, 125.7, 122.1, 121.7, 78.9, 71.9, 33.5, 17.7. HRMS (EI, 70 eV) $\mathrm{m} / \mathrm{z}$ calcd. for $\mathrm{C}_{19} \mathrm{H}_{16} \mathrm{~N}_{3} \mathrm{O}_{2}\left([\mathrm{M}+\mathrm{H}]^{+}\right)$: 318.1243 . Found: 318.1238 .

N-(3,5-Dimethoxyphenyl)-4-oxo-3-(prop-2-yn-1-yl)-3,4-dihydroquinazoline-2-carboxamide (5d). Yield: $885 \mathrm{mg}(81 \%)$, colourless crystals, mp 208-210 ${ }^{\circ} \mathrm{C}$ (ethyl acetate). IR (KBr): 3336, 3260, 3044, 2974, 2940, 2840, 1696, 1602, 1534, 1464, 1408, 1382, 1360, 1332, 1298, 1242, 1202, 1154, 1064, 1034, 972, 956, 938, 896, 844, 810, 768, 730, 694, 678, 636, 582, 522, $494 \mathrm{~cm}^{-1}$; MS (EI, $\left.70 \mathrm{eV}\right) \mathrm{m} / \mathrm{z}: 364$ (19\%), 363 (78, M+ ), 362 (68), 348 (33), 335 (45), 332 (100), 320 (34), 190 (61), 184 (62), 156 (42), 155 (53), 145 (46), 129 (69), 119 (89), 102 (31), 90 (44); ${ }^{1} \mathrm{H}-\mathrm{NMR}\left(\mathrm{CDCl}_{3}\right) \delta$ : 9.60 (s, 1H, amide-H), $8.35(\mathrm{~d}, J=7.8 \mathrm{~Hz}, 1 \mathrm{H}, 5-\mathrm{H}), 7.87-7.77(\mathrm{~m}, 2 \mathrm{H}, 7-\mathrm{H}, 8-\mathrm{H}), 7.61(\mathrm{t}, J=7.2 \mathrm{~Hz}, 1 \mathrm{H}, 6-\mathrm{H}), 6.95(\mathrm{~d}$, $J=1.8 \mathrm{~Hz}, 2 \mathrm{H}$, phenyl 2'-H, 6'-H), 6.33 (t, unresolved, $1 \mathrm{H}$, phenyl $\left.4^{\prime}-\mathrm{H}\right), 5.59$ (d, $J=2.1 \mathrm{~Hz}, 2 \mathrm{H}$, 
$\left.\mathrm{CH}_{2}\right), 3.84\left(\mathrm{~s}, 6 \mathrm{H}, \mathrm{OCH}_{3}\right), 2.28(\mathrm{t}, J=2.1 \mathrm{~Hz}, 1 \mathrm{H}, \mathrm{C} \equiv \mathrm{CH}) ;{ }^{13} \mathrm{C}-\mathrm{NMR}\left(\mathrm{CDCl}_{3}\right) \delta: 161.2,158.1,145.4$, 144.9, 138.5, 134.9, 128.9, 127.7, 127.5, 121.7, 98.6, 97.6, 78.8, 72.0, 55.5, 33.6. HRMS (EI, 70 eV) $\mathrm{m} / z$ calcd. for $\mathrm{C}_{20} \mathrm{H}_{18} \mathrm{~N}_{3} \mathrm{O}_{4}\left([\mathrm{M}+\mathrm{H}]^{+}\right)$: 364.1297. Found: 364.1303 .

$\mathrm{N}$-(4-Nitrophenyl)-4-oxo-3-(prop-2-yn-1-yl)-3,4-dihydroquinazoline-2-carboxamide (5e). Yield: $565 \mathrm{mg}$ (54\%), colourless crystals, mp 204-206 ${ }^{\circ} \mathrm{C}\left(\mathrm{DMF} / \mathrm{CHCl}_{3}\right)$. IR (KBr): 3298, 3270, 3158, 3094, 3008, 1696, 1664, 1614, 1586, 1556, 1512, 1426, 1340, 1306, 1248, 1166, 1110, 1042, 982, 946, 902, 856, 786, 750, 696, 648, 562, 520, $492 \mathrm{~cm}^{-1}$; MS (EI, $\left.70 \mathrm{eV}\right) \mathrm{m} / \mathrm{z}: 348\left(\mathrm{M}^{+}, 41 \%\right), 347$ (100), 319 (54), 301 (35), 155 (26), 129 (35), 119 (35), 90 (33); ${ }^{1} \mathrm{H}-\mathrm{NMR}$ (DMSO-d $) \delta: 11.72$ (s, 1H, amide-H), 8.32-8.28 (BB' part of an $\mathrm{AA}^{\prime} \mathrm{BB}^{\prime}$ system, 2H, phenyl 3'-H, 5'-H), 8.25-8.22 (m, 1H, 5-H), 8.06-8.00 (AA' part of an AA'BB' system, 2H, phenyl 2'-H, 6'-H), 7.99-7.92 (m, 1H, 7-H), $7.86(\mathrm{~d}, J=7.8 \mathrm{~Hz}, 1 \mathrm{H}, 8-\mathrm{H})$, $7.72-7.66(\mathrm{~m}, 1 \mathrm{H}, 6-\mathrm{H}), 5.06\left(\mathrm{~d}, J=2.4 \mathrm{~Hz}, 2 \mathrm{H}, \mathrm{CH}_{2}\right), 2.50$ (overlapped by solvent signal, $1 \mathrm{H}$, $\mathrm{C} \equiv \mathrm{CH}) ;{ }^{13} \mathrm{C}-\mathrm{NMR}\left(\mathrm{DMSO}-d_{6}\right) \delta: 160.0,159.7,147.5,145.4,143.8,143.3,135.3,128.9,127.7,126.6$, 124.9, 121.0, 120.2, 78.3, 75.2, 33.1. HRMS (EI, $70 \mathrm{eV}) \mathrm{m} / z$ calcd. for $\mathrm{C}_{18} \mathrm{H}_{11} \mathrm{~N}_{4} \mathrm{O}_{4}\left([\mathrm{M}-\mathrm{H}]^{+}\right)$: 347.0780. Found: 347.0791.

$\mathrm{N}$-(4-Cyanophenyl)-4-oxo-3-(prop-2-yn-1-yl)-3,4-dihydroquinazoline-2-carboxamide (5f). Yield: $765 \mathrm{mg}$ (78\%), colourless crystals, mp 199-201 ${ }^{\circ} \mathrm{C}\left(\mathrm{CHCl}_{3}\right)$. IR (KBr): 3300, 3258, 3180, 3108, 3058, 2998, 2224, 1692, 1660, 1598, 1536, 1508, 1474, 1432, 1408, 1390, 1318, 1246, 1230, 1176, 1164, 1110, 1042, 984, 948, 902, 840, 792, 770, 708, 694, 646, 550, 526, $508 \mathrm{~cm}^{-1}$; MS (EI, $\left.70 \mathrm{eV}\right) \mathrm{m} / \mathrm{z}: 328(\mathrm{M}+$, 33\%), 327 (100), 299 (45), 155 (15), 129 (17), 119 (22), 102 (18), 90 (16); ${ }^{1}$ H-NMR (DMSO-d 6 ) $\delta:$ 11.56 (s, 1H, amide-H), 8.24 (d, $J=7.8 \mathrm{~Hz}, 1 \mathrm{H}, 5-\mathrm{H}), 8.00-7.82(\mathrm{~m}, 6 \mathrm{H}, 7-\mathrm{H}, 8-\mathrm{H}$, phenyl 2'-H, 3'-H, 5'-H, 6'-H), 7.69 (t, $J=7.6 \mathrm{~Hz}, 1 \mathrm{H}, 6-\mathrm{H}), 5.05$ (d, $J=1.2 \mathrm{~Hz}, 2 \mathrm{H}, \mathrm{CH}_{2}$ ), 2.50 (overlapped by solvent signal, $1 \mathrm{H}, \mathrm{C} \equiv \mathrm{CH}$ ); ${ }^{13} \mathrm{C}-\mathrm{NMR}\left(\mathrm{DMSO}-d_{6}\right) \delta: 160.0,159.7,147.7,145.5,142.0,135.3,133.4,128.8$, 127.7, 126.6, 121.1, 120.4, 118.8, 106.6, 78.3, 75.2, 33.1. HRMS (EI, $70 \mathrm{eV}$ ) m/z calcd. for $\mathrm{C}_{19} \mathrm{H}_{11} \mathrm{~N}_{4} \mathrm{O}_{2}\left([\mathrm{M}-\mathrm{H}]^{+}\right): 327.0892$. Found: 327.0884 .

General Procedure for the Synthesis of the Substituted Luotonin A Derivatives 8b-f. To a solution of triphenylphosphine oxide $(835 \mathrm{mg}, 3 \mathrm{mmol})$ in dry $\mathrm{CH}_{2} \mathrm{Cl}_{2}(22 \mathrm{~mL})$ was dropwise added trifluoromethanesulfonic anhydride $(0.25 \mathrm{~mL}, 1.5 \mathrm{mmol})$ at $0{ }^{\circ} \mathrm{C}$ under argon, and the mixture was stirred at the same temperature for $15 \mathrm{~min}$. Then, the educt $5(1 \mathrm{mmol})$ was added in one portion at $0{ }^{\circ} \mathrm{C}$, and the mixture was stirred for $1 \mathrm{~h}$ (for 8e: $24 \mathrm{~h}$ ) while slowly warming to room temperature. Work-up for compounds $\mathbf{8 b}, \mathbf{8 c}, \mathbf{8 d}$, and $\mathbf{8 f}$ (for $\mathbf{8 e}$, see below): the reaction was quenched by addition of $10 \%$ aqueous $\mathrm{NaHCO}_{3}(15 \mathrm{~mL})$. The phases were separated and the aqueous layer was exhaustively extracted with $\mathrm{CH}_{2} \mathrm{Cl}_{2}$. The combined organic layers were washed with water and brine, dried $\left(\mathrm{Na}_{2} \mathrm{SO}_{4}\right)$ and evaporated. The residue was triturated with $\mathrm{CHCl}_{3}$ and filtered; the crude material thus obtained was recrystallised from the appropriate solvent.

2-Chloroquinolino[2',3':3,4]pyrrolo[2,1-b]quinazolin-11(13H)-one (2-Chloroluotonin A) [19] (8b). Yield: $313 \mathrm{mg}(98 \%)$, pale yellow needles, $\mathrm{mp}>330{ }^{\circ} \mathrm{C}$ decomp. $\left(\mathrm{CHCl}_{3}\right)$ (lit.[19] mp 233-234 $\left.{ }^{\circ} \mathrm{C}\right)$. IR (KBr): 3082, 3064, 2964, 1674, 1630, 1604, 1488, 1466, 1388, 1352, 1232, 1168, 1140, 1072, 1028, 928, 902, 836, 766, 738, 690, 662, 600, 524, $478 \mathrm{~cm}^{-1}$; MS (EI, $\left.70 \mathrm{eV}\right) \mathrm{m} / \mathrm{z}: 321\left(\mathrm{M}^{+}, 28 \%\right), 320$ (21), $319\left(\mathrm{M}^{+}, 100\right), 284$ (20), 77 (20), 76 (18), 63 (17), 50 (18); ${ }^{1} \mathrm{H}-\mathrm{NMR}\left(\mathrm{CDCl}_{3}\right) \delta: 8.43$ (dd, $J=9.0 \mathrm{~Hz}$, 
$0.9 \mathrm{~Hz}, 1 \mathrm{H}, 10-\mathrm{H}$, shows NOE on irradiation at 7.63-7.57 ppm), $8.41(\mathrm{~d}, J=9.0 \mathrm{~Hz}, 1 \mathrm{H}, 4-\mathrm{H}$, shows NOE on irradiation at $7.79 \mathrm{ppm}), 8.38(\mathrm{~s}, 1 \mathrm{H}, 14-\mathrm{H}$, shows NOE on irradiation at $5.36 \mathrm{ppm}$ and at $7.95 \mathrm{ppm}$ ), 8.12 (dd, $J=8.1 \mathrm{~Hz}, 0.6 \mathrm{~Hz}, 1 \mathrm{H}, 7-\mathrm{H}), 7.95$ (d, $J=2.4 \mathrm{~Hz}, 1 \mathrm{H}, 1-\mathrm{H}), 7.90-7.84$ (m, 1H, $8-\mathrm{H}$, shows NOE on irradiation at $8.12 \mathrm{ppm}$, at $8.12 \mathrm{ppm}$, or at $7.63-7.57 \mathrm{ppm}), 7.79(\mathrm{dd}, J=9.0 \mathrm{~Hz}$, $2.4 \mathrm{~Hz}, 1 \mathrm{H}, 3-\mathrm{H}), 7.63-7.57(\mathrm{~m}, 1 \mathrm{H}, 9-\mathrm{H}), 5.36\left(\mathrm{~s}, 2 \mathrm{H}, \mathrm{CH}_{2}\right) ;{ }^{13} \mathrm{C}-\mathrm{NMR}\left(\mathrm{CDCl}_{3}\right)$ 8: 155.2, 149.3, $147.9,134.7,133.0,132.2$, 131.8, 130.6, 130.4, 129.3, 128.8, 127.6, 126.6, 126.5, 121.9, 121.4, 47.3.

4-Methylquinolino[2',3':3,4]pyrrolo[2,1-b]quinazolin-11(13H)-one (4-Methylluotonin A) [11] (8c). Yield: $245 \mathrm{mg}(82 \%)$, colourless needles, mp 286-288 ${ }^{\circ} \mathrm{C}\left(\mathrm{CHCl}_{3}\right)$ (lit. [11] mp 294-295 $\left.{ }^{\circ} \mathrm{C}\right)$. IR (KBr): 3516, 3446, 3064, 2918, 1680, 1628, 1606, 1500, 1464, 1442, 1376, 1348, 1316, 1276, 1234, 1184, 1158, 1106, 1026, 908, 774, 760, 692, 664, 648, $508 \mathrm{~cm}^{-1}$; MS (EI, $\left.70 \mathrm{eV}\right) \mathrm{m} / z: 300\left([\mathrm{M}+1]^{+}\right.$, 19\%), $299\left(\mathrm{M}^{+}, 100\right), 284$ (6), 150 (7), 135 (7), 122 (7); ${ }^{1} \mathrm{H}-\mathrm{NMR}\left(\mathrm{CDCl}_{3}\right) \delta: 8.41$ (dd, $J=7.8 \mathrm{~Hz}, 1.5$ $\mathrm{Hz}, 1 \mathrm{H}, 10-\mathrm{H}), 8.38(\mathrm{~s}, 1 \mathrm{H}, 14-\mathrm{H}$, shows NOE on irradiation at $5.31 \mathrm{ppm}$ or at $7.76 \mathrm{ppm}), 8.07(\mathrm{dd}, J=8.1$ $\mathrm{Hz}, 0.6 \mathrm{~Hz}, 1 \mathrm{H}, 7-\mathrm{H}$, shows NOE on irradiation at 7.87-7.81 ppm), 7.87-7.81 (m, 1H, 8-H, shows NOE on irradiation at $8.07 \mathrm{ppm}), 7.76(\mathrm{~d}, J=8.1 \mathrm{~Hz}, 1 \mathrm{H}, 1-\mathrm{H}), 7.68(\mathrm{~d}, J=8.1 \mathrm{~Hz}, 1 \mathrm{H}, 3-\mathrm{H}$, shows NOE on irradiation at $3.03 \mathrm{ppm}), 7.59-7.53(\mathrm{~m}, 2 \mathrm{H}, 2-\mathrm{H}, 9-\mathrm{H}$, shows NOE on irradiation at $7.76 \mathrm{ppm}$ or at 7.87-7.81 ppm), $5.31\left(\mathrm{~s}, 2 \mathrm{H}, \mathrm{CH}_{2}\right), 3.03\left(\mathrm{~s}, 3 \mathrm{H}, \mathrm{CH}_{3}\right) ;{ }^{13} \mathrm{C}-\mathrm{NMR}\left(\mathrm{CDCl}_{3}\right) \delta: 160.7,152.9,150.2$, 149.4, 148.7, 139.0, 134.4, 131.6, 130.7, 129.3, 128.8, 128.4, 127.3, 126.4, 125.9, 121.3, 47.2, 18.4. HRMS (EI, $70 \mathrm{eV}) \mathrm{m} / z$ calcd. for $\mathrm{C}_{19} \mathrm{H}_{13} \mathrm{~N}_{3} \mathrm{O}\left(\mathrm{M}^{+}\right)$: 299.1059. Found: 299.1053.

1,3-Dimethoxyquinolino[2',3':3,4]pyrrolo[2,1-b]quinazolin-11(13H)-one (1,3-Dimethoxyluotonin A) (8d). Yield: $290 \mathrm{mg}(84 \%)$, pale yellow needles, mp $295-297{ }^{\circ} \mathrm{C}\left(\mathrm{CHCl}_{3}\right)$. IR (KBr): 3066, 3016, 2940, 2838, 1680, 1624, 1580, 1504, 1466, 1408, 1392, 1366, 1332, 1302, 1256, 1212, 1154, 1144, 1094, 1042, 1020, 902, 830, 776, 692, 660, 586, $526 \mathrm{~cm}^{-1}$; MS (EI, $\left.70 \mathrm{eV}\right) \mathrm{m} / \mathrm{z}: 346\left([\mathrm{M}+1]^{+}, 22 \%\right)$, $345\left(\mathrm{M}^{+}, 100\right), 331$ (7), 330 (33), 287 (15), 259 (10), 173 (9), 129 (7); ${ }^{1} \mathrm{H}-\mathrm{NMR}\left(\mathrm{CDCl}_{3}\right) \delta: 8.73$ (s, $1 \mathrm{H}, 14-\mathrm{H}$, shows NOE on irradiation at $5.27 \mathrm{ppm}), 8.42(\mathrm{~d}, J=8.1 \mathrm{~Hz}, 1 \mathrm{H}, 10-\mathrm{H}), 8.10(\mathrm{~d}, J=7.8 \mathrm{~Hz}$, 1H, 7-H), 7.87-7.81 (m, 1H, 8-H), 7.59-7.54 (m, 1H, 9-H), 7.37 (d, J = 1.5 Hz, 1H, 4-H), 6.60 (d, $J=2.4 \mathrm{~Hz}, 1 \mathrm{H}, 2-\mathrm{H}), 5.27\left(\mathrm{~s}, 2 \mathrm{H}, \mathrm{CH}_{2}\right), 4.01\left(\mathrm{~s}, 3 \mathrm{H}, 1-\mathrm{OCH}_{3}\right.$, shows NOE on irradiation at $\left.8.73 \mathrm{ppm}\right)$, $3.98\left(\mathrm{~s}, 3 \mathrm{H}, 3-\mathrm{OCH}_{3}\right.$, shows NOE on irradiation at $\left.7.37 \mathrm{ppm}\right) ;{ }^{13} \mathrm{C}-\mathrm{NMR}\left(\mathrm{CDCl}_{3}\right) \delta: 162.2,160.7$, $155.8,152.9,151.8,151.5,149.5,134.4,128.7,127.2,126.9,126.5,126.4,121.3,117.9,100.6,100.0$, 56.0, 55.8, 47.5. HRMS (EI, $70 \mathrm{eV}) \mathrm{m} / z$ calcd. for $\mathrm{C}_{20} \mathrm{H}_{16} \mathrm{~N}_{3} \mathrm{O}_{3}\left([\mathrm{M}+\mathrm{H}]^{+}\right): 346.1192$, Found: 346.1190 .

2-Nitroquinolino[2',3':3,4]pyrrolo[2,1-b]quinazolin-11(13H)-one (2-Nitroluotonin A) (8e). The reaction mixture was evaporated under reduced pressure and the residue was treated with $10 \%$ aqueous $\mathrm{NaHCO}_{3}(5 \mathrm{~mL})$, followed by dilution with water $(100 \mathrm{~mL})$. The mixture was stirred at room temperature for $1 \mathrm{~h}$, then the solid was collected by filtration, washed with water and dried. The material was taken up in $\mathrm{CHCl}_{3}(10 \mathrm{~mL})$ and it was briefly refluxed. The suspension was filtered while hot and the solid was washed with hot $\mathrm{CHCl}_{3}$ and dried to afford $230 \mathrm{mg}(69 \%)$ of $8 \mathrm{e}$ as colourless crystals, $\mathrm{mp}>330^{\circ} \mathrm{C}$ decomp. (DMF). IR (KBr): 3068, 3006, 2938, 1674, 1630, 1606, 1578, 1528, 1490, 1464, 1404, 1344, 1300, 1234, 1174, 1140, 1084, 942, 906, 856, 828, 774, 734, 692, 654, 598, 536, 486, $466 \mathrm{~cm}^{-1}$; MS (EI, $\left.70 \mathrm{eV}\right) \mathrm{m} / z: 331$ ([M+1] $\left.]^{+}, 20 \%\right), 330\left(\mathrm{M}^{+}, 100\right), 284$ (72), $272(19), 128$ (18), 77 (21), 76 (19), 63 (17); ${ }^{1} \mathrm{H}-\mathrm{NMR}\left(\mathrm{DMSO}-d_{6}\right) \delta: 9.20$ (s, 1H, 1-H), 9.05 (s, 1H, 14-H), 8.54 (d, 
$J=9.0 \mathrm{~Hz}, 1 \mathrm{H}, 3-\mathrm{H}), 8.44(\mathrm{~d}, J=9.0 \mathrm{~Hz}, 1 \mathrm{H}, 4-\mathrm{H}), 8.27$ (d, $J=7.5 \mathrm{~Hz}, 1 \mathrm{H}, 10-\mathrm{H}), 7.99-7.88$ (m, 2H, 7-H, 8-H), $7.64(\mathrm{t}$, unresolved, $1 \mathrm{H}, 9-\mathrm{H}), 5.35\left(\mathrm{~s}, 2 \mathrm{H}, \mathrm{CH}_{2}\right) ;{ }^{13} \mathrm{C}-\mathrm{NMR}$ (DMSO- $\left.d_{6}\right) \delta: 159.5,155.1$, 152.4, 150.1, 148.8, 145.9, 134.6, 134.1, 132.7, 131.5, 128.2, 127.6, 127.5, 125.9, 125.4, 123.5, 121.2, 47.6. HRMS (EI, $70 \mathrm{eV}) \mathrm{m} / z$ calcd. for $\mathrm{C}_{18} \mathrm{H}_{10} \mathrm{~N}_{4} \mathrm{O}_{3}\left(\mathrm{M}^{+}\right)$: 330.0753 . Found: 330.0751 .

11-Oxo-11,13-dihydroquinolino[2',3':3,4]pyrrolo[2,1-b]quinazoline-2-carbonitrile (2-Cyanoluotonin A) (8f). Yield: $168 \mathrm{mg}(54 \%)$, colourless crystals, $\mathrm{mp}>330{ }^{\circ} \mathrm{C}$ decomp. $\left(\mathrm{CHCl}_{3}\right)$. IR ( $\left.\mathrm{KBr}\right): 3058,3004$, 2954, 2226, 1676, 1628, 1604, 1498, 1464, 1438, 1410, 1372, 1354, 1334, 1238, 1182, 1152, 1028, 932, 906, 832, 778, 692, 656, 598, 528, $482 \mathrm{~cm}^{-1}$; MS (EI, $\left.70 \mathrm{eV}\right) \mathrm{m} / z: 311\left([\mathrm{M}+1]^{+}, 16 \%\right), 310\left(\mathrm{M}^{+}\right.$, 100), 282 (12), 281 (7), 254 (7), 141 (5); ${ }^{1} \mathrm{H}-\mathrm{NMR}$ (DMSO-d $)$ ) $\delta: 8.87$ (s, 1H, 14-H), 8.86 (d, $J=1.8 \mathrm{~Hz}$, $1 \mathrm{H}, 1-\mathrm{H}), 8.41(\mathrm{~d}, J=8.7 \mathrm{~Hz}, 1 \mathrm{H}, 4-\mathrm{H}), 8.30(\mathrm{~d}, J=7.8 \mathrm{~Hz}, 1 \mathrm{H}, 10-\mathrm{H}), 8.17$ (dd, $J=8.7 \mathrm{~Hz}, 1.8 \mathrm{~Hz}, 1 \mathrm{H}$, 3-H), 7.96-7.93 (m, 2H, 7-H, 8-H), 7.68-7.62 (m, 1H, 9-H), 5.35 (s, 2H, $\left.\mathrm{CH}_{2}\right) ;{ }^{13} \mathrm{C}-\mathrm{NMR}$ (DMSO- $d_{6}$ ) $\delta: 159.6,154.5,152.5,149.1,148.9,135.3,134.6,132.7,132.6,131.1,130.9,128.2,127.7,127.5$, 125.9, 121.2, 118.4, 110.5, 47.7. HRMS (EI, $70 \mathrm{eV}) \mathrm{m} / z$ calcd. for $\mathrm{C}_{19} \mathrm{H}_{10} \mathrm{~N}_{4} \mathrm{O}\left(\mathrm{M}^{+}\right): 310.0855$. Found: 310.0862 .

4-Oxo-N-(pyridin-4-yl)-3,4-dihydroquinazoline-2-carboxamide (9). To a solution of 4-aminopyridine $(753 \mathrm{mg}, 8 \mathrm{mmol})$ in dry 1,2-dichloroethane $(20 \mathrm{~mL})$ under argon was added dropwise a $2 \mathrm{M}$ solution of $\mathrm{AlMe}_{3}(4.0 \mathrm{~mL}, 8 \mathrm{mmol})$ in heptane. The mixture was stirred for $30 \mathrm{~min}$ at room temperature, then the ester 1 (1.091 g, $5 \mathrm{mmol}$ ) was added in one portion, and the mixture was refluxed for $2 \mathrm{~h}$. After cooling to $0{ }^{\circ} \mathrm{C}$, it was then quenched by slow addition of $2 \mathrm{~N} \mathrm{HCl}(20 \mathrm{~mL})$, followed by water $(80 \mathrm{~mL})$. The two clear phases were separated and the aqueous phase was brought to $\mathrm{pH} \mathrm{6-7} \mathrm{by} \mathrm{addition} \mathrm{of} 2 \mathrm{~N}$ ammonia under ice-cooling. The resulting suspension was kept in the refrigerator overnight, then the product was collected by filtration, washed with water and dried to afford $960 \mathrm{mg}(72 \%)$ of 9 as colourless crystals, mp 304-306 ${ }^{\circ} \mathrm{C}(\mathrm{EtOH}) . \mathrm{MS}(\mathrm{EI}, 70 \mathrm{eV}) \mathrm{m} / z: 266\left(\mathrm{M}^{+}, 68 \%\right), 238$ (26), 146 (70), 121 (77), 119 (100), 118 (20), 90 (38), 64 (18), 63 (17), 51 (17); ${ }^{1} \mathrm{H}-\mathrm{NMR}$ (DMSO- $d_{6}$ ) $\delta: 12.59$ (br, 1H, 3-H), 11.12 (br, 1H, amide-H), 8.60-8.48 (m, unresolved, 2H, pyridine $\left.2^{\prime}-\mathrm{H}, 6^{\prime}-\mathrm{H}\right), 8.20$ (d, $J=7.8 \mathrm{~Hz}$, $1 \mathrm{H}, 5-\mathrm{H}), 7.97-7.88\left(\mathrm{~m}, 4 \mathrm{H}, 7-\mathrm{H}, 8-\mathrm{H}\right.$, pyridine $3^{\prime}-\mathrm{H}, 5^{\prime}-\mathrm{H}$, shows NOE on irradiation at $11.12 \mathrm{ppm}$ or at $8.60-8.48 \mathrm{ppm}), 7.68-7.62(\mathrm{~m}, 1 \mathrm{H}, 6-\mathrm{H}$, shows $\mathrm{NOE}$ on irradiation at $8.20 \mathrm{ppm}) ;{ }^{13} \mathrm{C}-\mathrm{NMR}$ (DMSO- $\left.d_{6}\right) \delta: 160.9,159.1,150.3,146.7,145.4,144.5,134.8,128.4,127.9,126.2,122.8,114.4$. Anal. calcd. for $\mathrm{C}_{14} \mathrm{H}_{10} \mathrm{~N}_{4} \mathrm{O}_{2} \cdot 0.5 \mathrm{H}_{2} \mathrm{O}$ : C, 61.09; H, 4.03; N, 20.35. Found: C, 61.08; H, 3.73; N, 20.20.

4-Oxo-3-(prop-2-yn-1-yl)-N-(pyridin-4-yl)-3,4-dihydroquinazoline-2-carboxamide (10). To a suspension of 9 (666 mg, $2.5 \mathrm{mmol})$ in DMF $(15 \mathrm{~mL})$ wass added $\mathrm{K}_{2} \mathrm{CO}_{3}(414 \mathrm{mg}, 3 \mathrm{mmol})$ and propargyl bromide (446 $\mathrm{mg}$ of an $80 \%$ solution in toluene, $3 \mathrm{mmol}$ ), and the mixture was stirred at room temperature for $24 \mathrm{~h}$. It was then poured into water $(50 \mathrm{~mL})$ and it was exhaustively extracted with $\mathrm{CH}_{2} \mathrm{Cl}_{2}$. The combined extracts were washed with water and brine, dried over $\mathrm{Na}_{2} \mathrm{SO}_{4}$, and evaporated. The residue was purified by column chromatography $\left(\mathrm{CH}_{2} \mathrm{Cl}_{2} / \mathrm{MeOH}, 19+1\right)$, followed by recrystallisation from ethyl acetatre/light petroleum to give $365 \mathrm{mg}(48 \%)$ of $\mathbf{1 0}$ as colourless crystals, mp 183-185 ${ }^{\circ} \mathrm{C}$. MS (EI, $\left.70 \mathrm{eV}\right) \mathrm{m} / \mathrm{z}: 304\left(\mathrm{M}^{+}, 31 \%\right), 303$ (100), 275 (58), 155 (35), 145 (23), 131 (34), 129 (44), 121 (32), 119 (37), 90 (27), 78 (28), 57 (33), 51 (53); ${ }^{1} \mathrm{H}-\mathrm{NMR}\left(\mathrm{CDCl}_{3}\right)$ 8: 10.02 (br, $1 \mathrm{H}$, amide-H), $8.60\left(\mathrm{~d}, J=5.7 \mathrm{~Hz}, 2 \mathrm{H}\right.$, pyridine $\left.2^{\prime}-\mathrm{H}, 6^{\prime}-\mathrm{H}\right), 8.34(\mathrm{dd}, J=6.9 \mathrm{~Hz}, 0.9 \mathrm{~Hz}, 1 \mathrm{H}, 5-\mathrm{H})$, 
7.86-7.81 (m, 1H, 7-H), $7.76(\mathrm{~d}, J=7.5 \mathrm{~Hz}, 1 \mathrm{H}, 8-\mathrm{H}), 7.68\left(\mathrm{~d}, J=5.7 \mathrm{~Hz}, 2 \mathrm{H}\right.$, pyridine $\left.3^{\prime}-\mathrm{H}, 5^{\prime}-\mathrm{H}\right)$, $7.64-7.58(\mathrm{~m}, 1 \mathrm{H}, 6-\mathrm{H}), 5.55\left(\mathrm{~d}, J=2.4 \mathrm{~Hz}, 2 \mathrm{H}, \mathrm{CH}_{2}\right), 2.28(\mathrm{t}, J=2.4 \mathrm{~Hz}, 1 \mathrm{H}, \mathrm{C} \equiv \mathrm{CH}) ;{ }^{13} \mathrm{C}-\mathrm{NMR}$ $\left(\mathrm{CDCl}_{3}\right) \delta: 160.9,158.7,150.9,144.6,144.5,143.8,135.0,129.3,127.7,127.5,121.8,113.9,78.6$, 72.2, 33.5. HRMS (EI, $70 \mathrm{eV}) \mathrm{m} / z$ calcd. for $\mathrm{C}_{17} \mathrm{H}_{12} \mathrm{~N}_{4} \mathrm{O}_{2}\left(\mathrm{M}^{+}\right)$: 304.0960. Found: 304.0953.

4-Oxo-N-(2-thienyl)-3,4-dihydroquinazoline-2-carboxamide (11). To an ice-cooled solution of tert-butyl $\mathrm{N}$-(2-thienyl)carbamate [14,26] $(1.995 \mathrm{~g}, 10 \mathrm{mmol})$ in $\mathrm{CH}_{2} \mathrm{Cl}_{2}(60 \mathrm{~mL})$ was added trifluoroacetic acid $(15 \mathrm{~mL})$, then the cooling bath was removed and the solution was stirred for $2 \mathrm{~h}$. It was then slowly added into a well-stirred, ice-cooled mixture of $\mathrm{CH}_{2} \mathrm{Cl}_{2}(200 \mathrm{~mL})$ and a solution of $\mathrm{Na}_{2} \mathrm{CO}_{3}(22.1 \mathrm{~g}$, $0.2 \mathrm{~mol})$ in water $(200 \mathrm{~mL})$. The phases were separated and the aqueous layer was extracted with $\mathrm{CH}_{2} \mathrm{Cl}_{2}(2 \times 100 \mathrm{~mL})$. The combined organic phases were washed with brine, dried over $\mathrm{Na}_{2} \mathrm{SO}_{4}$ and filtered. To this solution was added 1,2-dichloroethane $(30 \mathrm{~mL})$ and it was then concentrated under reduced pressure to approx. $25-30 \mathrm{~mL}$ (max. bath temperature $20^{\circ} \mathrm{C}$ ). This solution was transferred into a two-necked flask equipped with a rubber septum and a reflux condenser. Under argon atmosphere, a $2 \mathrm{M}$ solution of $\mathrm{AlMe}_{3}(4.0 \mathrm{~mL}, 8 \mathrm{mmol})$ in heptane was added dropwise at room temperature, and stirring was continued for $30 \mathrm{~min}$. The ester $1(1.091 \mathrm{~g}, 5 \mathrm{mmol})$ was added in one portion, and the mixture was refluxed for $2 \mathrm{~h}$. After cooling to $0{ }^{\circ} \mathrm{C}$, it was then quenched by slow addition of $2 \mathrm{~N} \mathrm{HCl}(20 \mathrm{~mL})$, followed by water $(80 \mathrm{~mL})$. The phases were separated and the aqueous layer was extracted with $\mathrm{CH}_{2} \mathrm{Cl}_{2}(3 \times 100 \mathrm{~mL})$. The combined organic layers were washed with water, dried over $\mathrm{Na}_{2} \mathrm{SO}_{4}$ and evaporated. The residue was purified by column chromatography $\left(\mathrm{CH}_{2} \mathrm{Cl}_{2} /\right.$ ethyl acetate, $6+1)$ to give $1.29 \mathrm{~g}(95 \%)$ of $\mathbf{1 1}$ as a yellow solid, $\mathrm{mp} 243-246{ }^{\circ} \mathrm{C}$. MS (EI, $\left.70 \mathrm{eV}\right) \mathrm{m} / \mathrm{z}: 271$ $\left(\mathrm{M}^{+}, 12 \%\right), 211$ (15), 210 (100), 119 (16), 117 (19), 91 (75), 77 (19), 57 (16); ${ }^{1} \mathrm{H}-\mathrm{NMR}$ (DMSO-d $) \delta$ : 12.53 (br, 1H, 3-H), 12.19 (br, 1H, amide-H), 8.20 (d, J=8.1 Hz, 1H, 5-H), 7.94-7.86 (m, 2H, 7-H, 8-H), 7.66-7.60 (m, 1H, 6-H), $7.22\left(\mathrm{~d}, J=3.9 \mathrm{~Hz}, 1 \mathrm{H}\right.$, thiophene $\left.3^{\prime}-\mathrm{H}\right), 7.11(\mathrm{~d}, J=4.8 \mathrm{~Hz}, 1 \mathrm{H}$, thiophene $\left.5^{\prime}-\mathrm{H}\right), 6.95\left(\mathrm{t}, J=4.5 \mathrm{~Hz}, 1 \mathrm{H}\right.$, thiophene $\left.4{ }^{\prime}-\mathrm{H}\right) ;{ }^{13} \mathrm{C}-\mathrm{NMR}$ (DMSO- $d_{6}$ ) $\delta: 160.8,156.4,146.9$, 145.2, 138.7, 134.7, 128.2, 127.8, 126.2, 124.4, 122.8, 118.5, 114.4. HRMS (EI, $70 \mathrm{eV}) \mathrm{m} / \mathrm{z}$ calcd. for $\mathrm{C}_{13} \mathrm{H}_{10} \mathrm{~N}_{3} \mathrm{O}_{2} \mathrm{~S}\left([\mathrm{M}+\mathrm{H}]^{+}\right): 272.0494$. Found: 272.0493 .

4-Oxo-3-(prop-2-yn-1-yl)-N-(2-thienyl)-3,4-dihydroquinazoline-2-carboxamide (12). To a suspension of $11(814 \mathrm{mg}, 3 \mathrm{mmol})$ in DMF $(20 \mathrm{~mL})$ wass added $\mathrm{K}_{2} \mathrm{CO}_{3}(455 \mathrm{mg}, 3.3 \mathrm{mmol})$ and propargyl bromide (490 $\mathrm{mg}$ of an $80 \%$ solution in toluene, $3.3 \mathrm{mmol}$ ), and the mixture was stirred at room temperature for $24 \mathrm{~h}$. It was then poured into water $(100 \mathrm{~mL})$ and it was extracted with ethyl acetate $(2 \times 100 \mathrm{~mL})$. The combined extracts were washed with water and brine, dried over $\mathrm{Na}_{2} \mathrm{SO}_{4}$, and evaporated. The residue was purified by column chromatography $\left(\mathrm{CH}_{2} \mathrm{Cl}_{2}\right)$ to give $780 \mathrm{mg}(84 \%)$ of 12 as a yellow solid, mp 208-210 ${ }^{\circ} \mathrm{C}$. MS (EI, $\left.70 \mathrm{eV}\right) \mathrm{m} / \mathrm{z}: 309\left(\mathrm{M}^{+}, 98 \%\right), 308$ (55), 292 (16), 281 (50), 276 (57), 183 (37), 156 (47), 155 (68), 145 (47), 136 (64), 129 (81), 119 (100), 97 (46), 90 (71); ${ }^{1} \mathrm{H}-\mathrm{NMR}\left(\mathrm{CDCl}_{3}\right) \delta: 10.41(\mathrm{br}, 1 \mathrm{H}$, amide-H), 8.37 (dd, $J=8.2 \mathrm{~Hz}, 1.1 \mathrm{~Hz}, 1 \mathrm{H}, 5-\mathrm{H}), 7.85(\mathrm{td}, J=7.5 \mathrm{~Hz}$, $1.3 \mathrm{~Hz}, 1 \mathrm{H}, 7-\mathrm{H}), 7.80(\mathrm{dd}, J=8.1 \mathrm{~Hz}, 1.0 \mathrm{~Hz}, 1 \mathrm{H}, 8-\mathrm{H}), 7.62(\mathrm{td}, J=7.5 \mathrm{~Hz}, 1.6 \mathrm{~Hz}, 1 \mathrm{H}, 6-\mathrm{H})$, 7.05-7.02 (m, 1H, thiophene 5'-H), 6.99-6.96 (m, 2H, thiophene $\left.3^{\prime}-\mathrm{H}, 4^{\prime}-\mathrm{H}\right), 5.65(\mathrm{~d}, J=2.4 \mathrm{~Hz}, 2 \mathrm{H}$, $\left.\mathrm{CH}_{2}\right), 2.26(\mathrm{t}, J=2.4 \mathrm{~Hz}, 1 \mathrm{H}, \mathrm{C} \equiv \mathrm{CH}) ;{ }^{13} \mathrm{C}-\mathrm{NMR}\left(\mathrm{CDCl}_{3}\right) \delta: 161.1,156.6,144.8,144.2,137.9,135.0$, 129.1, 127.7, 127.5, 124.5, 121.8, 119.1, 113.9, 78.7, 72.0, 33.6. HRMS (EI, $70 \mathrm{eV}) \mathrm{m} / \mathrm{z}$ calcd. for $\mathrm{C}_{16} \mathrm{H}_{12} \mathrm{~N}_{3} \mathrm{O}_{2} \mathrm{~S}\left([\mathrm{M}+\mathrm{H}]^{+}\right): 310.0650$. Found: 310.0648 . 
Thieno[3",2": 5',6']pyrido[2',3':3,4]pyrrolo[2,1-b]quinazolin-7(5H)-one (13). To a solution of triphenylphosphine oxide (835 mg, $3 \mathrm{mmol})$ in dry $\mathrm{CH}_{2} \mathrm{Cl}_{2}(22 \mathrm{~mL})$ was dropwise added trifluoromethanesulfonic anhydride $(0.25 \mathrm{~mL}, 1.5 \mathrm{mmol})$ at $0{ }^{\circ} \mathrm{C}$ under argon, and the mixture was stirred at the same temperature for $15 \mathrm{~min}$. Then, a suspension of 12 (309 $\mathrm{mg}, 1 \mathrm{mmol})$ in dry $\mathrm{CH}_{2} \mathrm{Cl}_{2}(20 \mathrm{~mL})$ was added over a period of $10 \mathrm{~min}$ at $0{ }^{\circ} \mathrm{C}$, and the mixture was stirred for $1 \mathrm{~h}$ while slowly warming to room temperature. The reaction was quenched by addition of $10 \%$ aqueous $\mathrm{NaHCO}_{3}(30 \mathrm{~mL})$. The phases were separated and the aqueous layer was exhaustively extracted with $\mathrm{CH}_{2} \mathrm{Cl}_{2}$. The combined organic layers were washed with water and brine, dried $\left(\mathrm{Na}_{2} \mathrm{SO}_{4}\right)$ and evaporated. The residue was purified by column chromatography $\left(\mathrm{CH}_{2} \mathrm{Cl}_{2}\right.$ /ethyl acetate, $\left.6+1\right)$, followed by recrystallisation from EtOH to afford $160 \mathrm{mg}(55 \%)$ of $\mathbf{1 3}$ as almost colourless needles, mp 318-321 ${ }^{\circ} \mathrm{C}$. MS (EI, $70 \mathrm{eV}$ ) m/z: 292 (19\%), $291\left(100, \mathrm{M}^{+}\right), 290$ (30), 263 (20), 262 (15), 236 (7), 235 (8), 146 (17), 131 (11), 118 (7), 105 (9), 77 (10); ${ }^{1} \mathrm{H}-\mathrm{NMR}\left(\mathrm{CDCl}_{3}\right)$ $\delta: ~ 8.45-8.40(\mathrm{~m}, 1 \mathrm{H}, 8-\mathrm{H}), 8.37$ (s, 1H, 4-H), 8.08-8.04 (m, $1 \mathrm{H}, 11-\mathrm{H}), 7.88-7.82(\mathrm{~m}, 1 \mathrm{H}, 10-\mathrm{H}), 7.80(\mathrm{~d}, J=6.3 \mathrm{~Hz}, 1 \mathrm{H}, 2-\mathrm{H}), 7.60-7.54(\mathrm{~m}, 1 \mathrm{H}, 9-\mathrm{H}), 7.42(\mathrm{~d}$, $J=6.3 \mathrm{~Hz}, 1 \mathrm{H}, 3-\mathrm{H}), 5.29\left(\mathrm{~s}, 2 \mathrm{H}, \mathrm{CH}_{2}\right) ;{ }^{13} \mathrm{C}-\mathrm{NMR}\left(\mathrm{CDCl}_{3}\right) \delta: 164.0,160.6,152.6,149.4,147.7,134.6$, 134.5, 131.3, 129.9, 128.5, 127.2, 126.4, 126.2, 121.3, 121.1, 47.4. Anal. calcd. for $\mathrm{C}_{16} \mathrm{H}_{9} \mathrm{~N}_{3} \mathrm{OS}$ : C, 65.97; H, 3.11; N, 14.42. Found: C, 66.15; H, 3.29; N, 13.93. HRMS (EI, $70 \mathrm{eV}) \mathrm{m} / \mathrm{z}$ calcd. for $\mathrm{C}_{16} \mathrm{H}_{10} \mathrm{~N}_{3} \mathrm{OS}\left([\mathrm{M}+\mathrm{H}]^{+}\right): 292.0546$. Found: 292.0550 .

\section{Conclusions}

By applying Weinreb's amidation method to the preparation of the anilide-type key intermediates, we achieved a significant improvement of Yao's synthetic route to luotonin A and A-ring modified derivatives thereof in terms of overall yields (8a: 65\%, 8b: 66\%, 8c: 47\%, 8d: 50\%, 8e: 30\%, 8f: $33 \%$; all isolated overall yields are based on commercially available anthranilamide as starting material), brevity and - most importantly — versatility with regard to the aromatic amine component, even if the latter has less favourable nucleophilicity, solubility and/or stability properties. This is demonstrated by the concise synthesis of a small library of luotonin A analogues, including a novel thiophene isoster of the alkaloid.

\section{Acknowledgements}

We are grateful to Æterna Zentaris GmbH, Frankfurt/Main (Germany) for the preliminary in-vitro evaluation of antitumor activity.

\section{References and Notes}

1. Ma, Z.-Z.; Hano, Y.; Nomura, T.; Chen, Y.-J. Two New Pyrroloquinazolinoquinoline Alkaloids from Peganum Nigellastrum. Heterocycles 1997, 46, 541-546.

2. Du, W. Towards New Anticancer Drugs: a Decade of Advances in Synthesis of Camptothecins and Related Alkaloids. Tetrahedron 2003, 59, 8649-8687.

3. Ma, Z.; Hano, Y.; Nomura, T. Luotonin A: a Lead Toward Anti-Cancer Agent Development. Heterocycles 2005, 65, 2203-2219. 
4. Huang, W.P.; Liu, J.L.; Wang, C.L. Progress in the Synthesis of Natural Product Luotonin A and its Derivatives. Chin. J. Org. Chem. 2009, 29, 1533-1543.

5. Liang, J.L.; Cha, H.C.; Jahng, Y. Recent Advances in the Studies on Luotonins. Molecules 2011, $16,4861-4883$.

6. Cagir, A.; Eisenhauer, B.M.; Gao, R.; Thomas, S.J.; Hecht, S.M. Synthesis and Topoisomerase I Inhibitory Properties of Luotonin A Analogues. Bioorg. Med. Chem. 2004, 12, 6287-6299.

7. Bowman, W.R.; Cloonan, M.O.; Fletcher, A.J.; Stein, T. Synthesis of Heteroarenes Using Cascade Radical Cyclisation via Iminyl Radicals. Org. Biomol. Chem. 2005, 3, 1460-1467.

8. Bowman, W.R.; Elsegood, M.R.J.; Stein, T.; Weaver, G.W. Radical Reactions with 3H-Quinazolin-4-ones: Synthesis of Deoxyvasicinone, Mackinazolinone, Luotonin A, Rutaecarpine and Tryptanthrin. Org. Biomol. Chem. 2007, 5, 103-113.

9. Nacro, K.; Zha, C.; Guzzo, P.R.; Herr, R.J.; Peace D.; Friedrich, T.D. Synthesis and Topoisomerase Poisoning Activity of A-Ring and E-Ring Substituted Luotonin A Derivatives. Bioorg. Med. Chem. 2007, 15, 4237-4246.

10. Twin, H.; Batey, R.A. Intramolecular Hetero Diels-Alder (Povarov) Approach to the Synthesis of the Alkaloids Luotonin A and Camptothecin. Org. Lett. 2004, 6, 4913-4916.

11. Tseng, M.-C.; Chu, Y.-W.; Tsai, H.-P.; Lin, C.-M.; Hwang, J.; Chu, Y.-H. One-Pot Synthesis of Luotonin A and its Analogues. Org. Lett. 2011, 13, 920-923.

12. Zhou, H.-B.; Liu, G.-S.; Yao, Z.-J. Short and Efficient Total Synthesis of Luotonin A and 22-Hydroxyacuminatine Using a Common Cascade Strategy. J. Org. Chem. 2007, 72, 6270-6272.

13. Koepfli, J.B.; Brockman, J.A.; Moffat, J. Structure of Febrifugine and Isofebrifugine. J. Am. Chem. Soc. 1950, 72, 3323.

14. Reisch, J.; Usifoh, C.O.; Oluwadiya, J.O. Acetylenic Chemistry. Part 17. Acetylenic Amides as Precursors for the Synthesis of 3-Propynyl-quinazolin-ones. J. Heterocycl. Chem. 1990, 27, 1953-1956.

15. Usifoh, C.O.; Scriba, G.K.E. Synthesis and Anticonvulsant Activity of Acetylenic Quinazolinone Derivatives. Arch. Pharm. (Weinheim) 2000, 333, 261-266.

16. Basha, A.; Lipton, M.; Weinreb, S.M. A mild, General Method for Conversion of Esters to Amides. Tetrahedron Lett. 1977, 18, 4171-4174.

17. Lipton, M.F.; Basha, A.; Weinreb, S.M. Conversion of Esters to Amides with Dimethylaluminum Amides: N,N-Dimethylcyclohexanecarboxamide. Org. Synth. 1979, 59, 49-53.

18. Martin, S.F.; Dwyer, M.P.; Lynch, C.L. Application of AlMe - Mediated Amidation Reactions to Solution Phase Peptide Synthesis. Tetrahedron Lett. 1998, 39, 1517-1520.

19. Rahman, A.F.M.M.; Kim, D.H.; Liang, J.L.; Lee, E.-S.; Na, Y.; Jun, K.-Y.; Kwon, Y.; Jahng, Y. Synthesis and Biological Properties of Luotonin A Derivatives. Bull. Korean Chem. Soc. 2008, 29, 1988-1992.

20. The main reason for the observed diminished reactivity of $\mathbf{5 e}$ and $\mathbf{5 f}$ might be the much poorer solubility of these substrates in the reaction medium.

21. Binder, D.; Habison, G.; Noe, C.R. A Simple Method for the Preparation of 2-Aminothiophenes. Synthesis 1977, 255-256.

22. There has been only one report so far, describing thiophene analogues of luotonin A, in this case ring $\mathrm{E}$ is replaced by a thiophene unit [6]. 
23. Nociari, M.M.; Shalev, A.; Benias, P.; Russo, C. A novel one-step, highly sensitive fluorometric assay to evaluate cell-mediated cytotoxicity. J. Immunol. Methods 1998, 213, 157-167.

24. $\mathrm{EC}_{50}$ value of compund $\mathbf{8 d}$ towards the Ishikawa cell line (ECACC 99040201, endometrium carcinoma): $5.84 \mu \mathrm{M}$ (luotonin $\mathrm{A}$ : no inhibition); $\mathrm{EC}_{50}$ value of compund $\mathbf{8 d}$ towards the MDA-MB-231 cell line (ATCC HTB-26, triple negative breast cancer): $31.82 \mu \mathrm{M}$ (luotonin A: $>100 \mu \mathrm{M})$. For the other cell lines (KB/HeLa, NCI-H460, A2780, MDA-MB-435S), the EC 50 value of $\mathbf{8 d}$ was $>100 \mu \mathrm{M}$.

25. Sherif, S.M.; Mohareb, R.M.; Elgemeie, G.E.H.; Singh, R.P. Nitriles in Heterocyclic Synthesis: 1-Cyanoformanilide as Precursor for a Variety of Heterocyclic Ring Systems. Heterocycles 1988, 27, 1579-1583.

26. Zhao, L.; Curran, P.J.; Belanger, D.B.; Hamann, B.; Reddy, P.A.; Paruch, K.; Guzi, T.J.; Dwyer, M.P.; Siddiqui, M.A.; Tadikonda, P.K. Preparation of Imidazopyrazines as Protein Kinase Inhibitors. PCT Int. Appl. (2007), WO 2007058942 A2 20070524; Chem. Abstr. 2007, 567437.

Sample Availability: Samples of some of the compounds are available from the authors.

(C) 2012 by the authors; licensee MDPI, Basel, Switzerland. This article is an open access article distributed under the terms and conditions of the Creative Commons Attribution license (http://creativecommons.org/licenses/by/3.0/). 